NBER WORKING PAPER SERIES

\title{
WHO REALLY BENEFITS FROM CONSUMPTION TAX CUTS? EVIDENCE FROM A LARGE VAT REFORM IN FRANCE.
}

\author{
Youssef Benzarti \\ Dorian Carloni \\ Working Paper 23848 \\ http://www.nber.org/papers/w23848 \\ NATIONAL BUREAU OF ECONOMIC RESEARCH \\ 1050 Massachusetts Avenue \\ Cambridge, MA 02138 \\ September 2017
}

The views expressed in this paper are the authors' and should not be interpreted as CBO's. We are thankful to Alan Auerbach, Hilary Hoynes and Emmanuel Saez for their continuous support and guidance throughout this project. We also thank David Cashin, Tuomas Kosonen, Jonathan Goupille-Lebret, David Seim, David Sraer, Alisa Tazhitdinova and Reed Walker for helpful suggestions and comments. The views expressed herein are those of the authors and do not necessarily reflect the views of the National Bureau of Economic Research.

NBER working papers are circulated for discussion and comment purposes. They have not been peer-reviewed or been subject to the review by the NBER Board of Directors that accompanies official NBER publications.

(C) 2017 by Youssef Benzarti and Dorian Carloni. All rights reserved. Short sections of text, not to exceed two paragraphs, may be quoted without explicit permission provided that full credit, including (๑) notice, is given to the source. 
Who Really Benefits from Consumption Tax Cuts? Evidence from a Large VAT Reform in France.

Youssef Benzarti and Dorian Carloni

NBER Working Paper No. 23848

September 2017

JEL No. H20,H22,H23

\begin{abstract}
In this paper we evaluate the incidence of a large cut in value-added taxes (VAT) for French sitdown restaurants. In contrast to previous studies that focus on prices only, we estimate its effect on four groups: workers, firm owners, consumers and suppliers of material goods. Using a difference-in-differences strategy on firm-level data we find that: (1) the effect on consumers was limited, (2) employees and sellers of material goods shared 25 and 16 percent of the total benefit, and (3) the reform mostly benefited owners of sit-down restaurants, who pocketed 41 percent of the tax cut.
\end{abstract}

Youssef Benzarti

Department of Economics

University of California, Los Angeles

Bunche Hall, 315 Portola Plaza

Los Angeles, CA 90095

and NBER

benzarti@econ.ucla.edu

Dorian Carloni

Congressional Budget Office

Dorian.Carloni@cbo.gov

An online appendix is available at http://www.nber.org/data-appendix/w23848 
The Value-Added Tax (VAT) is one of the most important taxes in the world. All developed economies - with the exception of the United States (US) - have adopted a form of VAT. ${ }^{1}$ VATs often represent the largest source of Government revenue, for example in the European Union (EU), they raise $30 \%$ of total tax revenue, or $12 \%$ of GDP. Some US politicians have proposed adopting a VAT, either as a replacement for other taxes or to fund specific Government programs. ${ }^{2}$ However, relatively little attention has been dedicated to this tax compared to other taxes. ${ }^{3}$ In this paper, we help fill this gap by analyzing the incidence of a large VAT cut for French sit-down restaurants.

Member States of the European Union have increasingly relied on sector-specific and general VAT cuts to stimulate the economy. Through these tax breaks, Governments generate windfalls for firms hoping they would use them to increase demand through price reductions, increase employee wages and firm investments. However, little is known about the efficacy of such fiscal policies. But these policies are often very expensive, for example it is estimated that the French sit-down restaurant VAT cut cost 3 billion euros in 2010, making it the fourth largest firm subsidies in France. ${ }^{4}$ Another large VAT cut, the one year temporary VAT reduction in the UK cost 12.4 billion pounds in 2009. ${ }^{5}$ This paper sheds light on the effect of VAT cuts and finds that they mostly benefit firm owners through increased profits.

Empirical studies on tax incidence have provided limited evidence on the effects of VAT changes on outcomes other than prices. Primarily because of data limitations, previous research has been unable to disentangle the effects of VATs on employees, suppliers of non-labor intermediate inputs and capital owners. ${ }^{6}$ One notable exception is Kosonen (2015) who estimates the incidence of a large VAT cut on hairdressers in Finland. While the dataset he uses would in principle allow him to estimate the full incidence of the VAT cut, the hairdressing sector relies substantially less on employees (most firm owners are the sole employees) and material goods (hairdressers require very little input costs) making the analysis on these two groups limited. Our paper helps fill this gap by being the first to provide a full incidence analysis of a large reduction in the VAT rate. In July

\footnotetext{
${ }^{1} 160$ countries have adopted a form of VAT since its creation in the 1950's in France.

${ }^{2}$ See for example Washington Post, May 27, 2009.

${ }^{3}$ See for example Hines and Desai (2005) and Slemrod (2011) for the effect of VAT on trade and Naritomi (2013) and Pomeranz (2015) on the evasion of VATs.

${ }^{4}$ In comparison, research and development credits cost 4 billion euros in 2010 in France.

${ }^{5}$ The standard VAT rate was cut from $17.5 \%$ to $15 \%$ from December 2008 to December 2009.

${ }^{6}$ See Houel (2010) and Lafféter and Sillard (2014) for an analysis of the incidence of the French sit-down restaurant VAT cut on prices, Carbonnier (2007) and Carbonnier (2008) for the effect of other VAT changes on prices and Chouinard and Perloff (2004), Doyle and Samphantharak (2008), Kopczuk et al. (2013)), Gruber and Köszegi (2004), Hanson and Sullivan (2009), and Kenkel (2005) the incidece of sales and excise taxes on prices in the US.
} 
2009, the VAT rate for meals consumed in sit-down restaurants was reduced from 19.6 percent to 5.5 percent, while the VAT rates applied to the rest of the economy were unaffected. To study the effects of the reform we combine information on national prices from the French National Institute of Statistics and Economic Studies (INSEE) and Eurostat with firm level data from AMADEUS (Bureau van Dijk). Our empirical analysis proceeds in two steps.

First, we use a difference-in-differences strategy and compare sit-down restaurants (our treatment group) to non-restaurant market services (our control group). We find that prices charged by sit-down restaurants decreased slightly after the tax cut. The reform also led to a moderate increase in the costs of both labor and non-labor intermediate inputs, and large increases in owners' profits. These findings imply that sit-down restaurant owners were the main beneficiaries of the tax cut, while the remaining windfall was shared between employees, consumers and suppliers of material goods.

Second, we build on the theoretical framework of Auerbach and Hines (2002) and use the reduced-form coefficients to develop a welfare analysis, in which we estimate the incidence of the VAT cut on consumers, employees, sellers of material goods and firm owners. Our estimates suggest that in the long-run (30 months after the reform) firm owners pocketed around 41 percent of the VAT cut, employees and sellers of material goods received around 25 and 16 percent respectively, while consumers received the remaining 18 percent.

Our study faces two main limitations. First, although we do have information on restaurants' employment, we do not have information on wages or other characteristics of employees. ${ }^{7}$ We use survey data on hours worked to provide evidence consistent with higher wages - rather than hours worked - driving the observed increase in labor costs. We also rule out the possibility that the cost of employees increases because firm owners are paying themselves as employees for tax purposes. ${ }^{8}$

The second limitation relates to the estimated effect on consumers. First, our measure focuses exclusively on prices paid and ignores changes in the quality of goods purchased. Second, our incidence analysis relies on national rather than firm-level price indexes. Therefore, we are unable to observe the price charged by each individual firm in our sample, but can only provide an estimate of the aggregate effect of the reform on prices. Given that balance sheet data is missing for very small firms, which are also less likely to react to the reform, it is probable that our estimate of the

\footnotetext{
${ }^{7}$ Firms' balance sheet data report the total cost of employees, which includes wages and the employer's share of payroll taxes.

${ }^{8}$ Payroll taxes are so high in France that payments in profits are almost always more tax advantageous than wages.
} 
incidence on consumers is biased upward. ${ }^{9}$

\section{Institutional Background}

\subsection{The 2009 VAT Reform}

Before the reform was implemented in 2009, the French restaurant industry had two different VAT regimes: a standard rate of 19.6 percent applied to sit-down meals, and a reduced rate of 5.5 percent for take-away meals. Following a campaign promise by then French President Jacques Chirac, France applied for an authorization to re-classify sit-down restaurants from the standard to the reduced VAT rate in 2002. The application was first turned down by the European Commission because of strong opposition by then German Chancellor Gerhard Schroder. After some negotiations between France and Germany, an agreement was reached on January 20, 2009 allowing all Member States to re-classify sit-down restaurants to the reduced rate. The reclassification was implemented in France on July 1st 2009.

The reform's main goals were to (a) decrease the price of meals consumed in sit-down restaurants, (b) stimulate employment and investment in the sit-down restaurant industry, where total turnover had declined by around 10 percent in the period 1995-2009, and (c) equalize the VAT rate between sit-down meals and take-away meals. Importantly, the French government gathered the representatives of the business associations of the restaurant sector (Etats généraux de la restauration) and asked them to commit to a non-binding agreement called Contrat d'Avenir three months before the reform was implemented. This agreement, which was signed on April 28th 2009, offered precise directives on how the tax cut should be used to benefit consumers, and to increase both employment and investment. ${ }^{10}$ However, the limited decrease in prices we observe in the 30 months following the reform signals that the Contrat d'Avenir played a limited role.

At the same time the French government removed a payroll subsidy to which all restaurants and hotels had been eligible since August 2004, and which had been introduced as a temporary measure to stimulate employment in restaurants and hotels. The monthly amount of the subsidy received for each employee hired depended on whether the worker was paid close to minimum wage, and on the tenure of the firm, and reached a maximum of 1,368 euros per year. ${ }^{11}$ While the timing

\footnotetext{
${ }^{9}$ Harju et al. (2017) focus on a VAT cut for sit-down restaurants in Finland and show that small firms are less likely to cut their prices than larger firms.

${ }^{10}$ See section A.1 in the appendix of the paper for details on the Contrat d'Avenir.

${ }^{11}$ See the appendix of the paper for more information on the subsidy program.
} 
of the subsidy removal overlapped with the VAT reform, previous studies have shown that the employment effects of the subsidy were limited. ${ }^{12}$ We discuss and address these concerns in more details in section 5 and conclude that the increase in wages we find is unlikely to be due to the effects of the removal of the payroll subsidy.

\subsection{Employment and Wages in the Restaurant Sector}

Restaurants are an important part of the economy in France. According to the INSEE, the share of consumer spending on restaurants has increased from 5.1 percent to 5.9 percent between 1960 and 2007, while the share on food expenditures has decreased from 31.4 percent to 21.9 percent. ${ }^{13}$ Around two thirds of consumer spending on food services outside the home goes to sit-down and fast-food restaurants, with the remaining third spent on caterers, canteens, bars and cafeterias.

While the industry has been growing over the years, the traditional structure of sit-down restaurants has not changed over time. According to FAFIH (2011), which reports employment characteristics for French restaurants and hotels, around 47 percent of workers were employed in establishments with less than 10 workers in 2010, while 14 percent were in restaurants or hotels with more than 50 workers. In addition, sit-down restaurants are highly labor-intensive: labor costs are a major cost in restaurants, and wage setting dynamics can be summarized as follows.

First, labor is not very flexible. Indeed, around 78 percent of individuals working in restaurants and hotels were hired with open-ended contracts (Contrat à Durée Indeterminée - CDI) in 2013, while around 16 percent had fixed-term contracts (Contrat à Durée Determinée - CDD). CDI are contracts that are very hard to revoke: if a worker is fired, employers can incur substantial penalties. It is also costly to fire a worker under a CDD contract, but employers are not required to extend expired contracts. ${ }^{14}$ The remaining share of workers is composed of apprentices, workers whose employment is subsidized by the government (Contrats Aidés), and owners, who account for 1.8 percent of the industry workforce.

Secondly, a considerable fraction of workers are minimum wage employees. The French minimum wage (SMIC, Salaire Minimum Interprofessionel de Croissance) is set at the national level and applies to all employees and types of firms. It is indexed to both inflation and past wage growth and is raised every year in July. The wage varies depending on the employee's tenure and job

\footnotetext{
${ }^{12}$ See for example Houel (2010) for a description of the effects of the subsidy program.

${ }^{13}$ See Consales et al. (2009) for a more detailed analysis.

${ }^{14}$ Details on these contractual forms can be found in appendix section A.3.
} 
category, and in 2015 started at 9.61 euros per hour. Seguin (2011) estimated that in restaurants and hotels, around 40 percent of employees were paid the minimum wage in 2003, compared to 12-15 percent nation-wide.

Lastly, wage setting is unaffected by collective bargaining because the industry is dominated by very small firms and collective agreements are very scarce (Fougère et al. (2010)). This feature differentiates the restaurant sector from other sectors of the economy, where annual wage negotiations between employer associations and union or employee representatives occurs at both the industry and company level.

\section{Data}

Our analysis combines firm-level balance sheet information with aggregate national price indexes in the period 2004-2012. Annual data on French firms' balance sheets come from the Bureau van Dijk (BvD) AMADEUS dataset, which covers all private firms reporting to local tax authorities and/or data collection agencies. ${ }^{15}$ The data include standard income statement and balance sheet information such as total turnover, cost of employees, profits, material costs, and firms' assets and liabilities. The data also contain detailed information on the industry in which the firm operates, which allows us to distinguish between sit-down restaurants and other firms operating in the restaurant industry, such as take-away restaurants. Industries are classified according to the NAF Rev.2 classification, the French national statistical classification of activities introduced in 2008. Each firm in the dataset is associated with a unique industry code, corresponding to its main activity. For instance, if a restaurant offers both sit-down and take-away services, it only receives one industry code. Although this could be a potential source of bias in our analysis, the data do not allow us to control for it. VAT rates do not specifically apply to restaurants but rather to goods. Therefore if a restaurant is classified as sit-down but offers take-out food, the VAT rate applied to this transaction should be the take-out rate. In practice, prices are VAT-inclusive and restaurants rarely charge different prices for sit-down and take-out meals.

We only consider unconsolidated balance sheets to avoid biasing our estimates with any reporting manipulation that could occur between a subsidiary and its parent company. Unconsolidated data constitute around 70 percent of observations in the AMADEUS data. ${ }^{16}$

\footnotetext{
${ }^{15}$ Access to AMADEUS was obtained through the Wharton Research Data Services (WRDS) license. The dataset includes around $1 / 3$ of French sit-down restaurants, and the universe comprises around 100,000 establishments per year.

${ }^{16}$ Most of the remaining share of firm level observations is constituted by firms with limited financial information.
} 
In addition, our analysis focuses on firms providing information on their number of employees. While only half of unconsolidated balance sheets contained in AMADEUS has information on the average number of employees, this information allows us to distinguish between the employment and wage effects of the reform. ${ }^{17}$

As shown in Table 1, which displays summary statistics for our treatment and control groups, this selection leaves us with 147,958 sit-down restaurants, 1,482,447 firms operating in non-restaurant market services, and 1,737,234 non-restaurant small firms in the period 2004-2012.

We are primarily interested in estimating the effect of the reform on the number of employees, the cost per employee (which includes wages, salaries and taxes on salaries), the return to owners of sit-down restaurants (which we call return to capital) and the cost of materials purchased by sitdown restaurants. While the number of employees, the cost per employee and cost of materials are measured directly in AMADEUS, the return to capital is a measure we compute by subtracting the cost of employees, the cost of materials and other expenses from a firm's total sales. The return to capital is therefore a residual measure which includes firm profits, depreciation, interest payments and expenses that are neither labor nor material goods expenses. ${ }^{18}$ Throughout the analysis, return to capital represents gross income received by firm owners, either in the current period (in the form of profits), or in the future (through investment in the current period):

$$
\text { Return to } \text { Capital }_{j}=\text { Sales }_{j}-\text { Material Costs }_{j}-\text { Cost of Employees }_{j}
$$

Monthly price data for sit-down meals consumed in France are from the French National Institute of Statistics (INSEE), while prices for our control groups are computed using Eurostat monthly price data. ${ }^{19}$ Eurostat provides information on the price of goods by 4-digit Classification of Individual Consumption According to Purpose (COICOP) as well as weights used to compute aggregate indexes. While we cannot distinguish between the price charged by small firms versus large firms, we use this information to compute the average price of goods sold in the economy in non-restaurant market services and non-restaurant firms.

Consolidated data account for only 0.2 percent of observations in the period 2004-2012.

${ }^{17}$ At the end of the paper we show that our evidence on aggregate outcomes is robust to including the full sample of firms, which includes those without employment information.

${ }^{18}$ For example, operating expenses (purchase of capital goods and supplies, repair and improvements, advertising and promotion, etc.), occupancy and utilities expenses (rent, real estate taxes, utilities, property insurance), as well as general and administrative expenses.

${ }^{19}$ The INSEE surveys around 200,000 commodities across 27,000 firms every month, from which it constructs its price indexes by consumption category. See Lafféter and Sillard (2014) for a detailed description of the INSEE survey methodology. 
Finally, we use information on hours and days worked per week from the labor force survey Enquete Emploi en Continu (EEC), which contains detailed information on employment (as well as unemployment and training activities) over the twelve months prior to the date of the interview. The survey samples around 400,000 individuals per year and interviews them for six quarters. It contains self-reported information on the industry of employment, the total number of hours worked during a reference week, and the number of hours worked above the legal limit set by French law.

\section{Empirical Strategy}

\subsection{Mean Impact Estimation}

In order to effectively model the mean impact of the VAT change, we use a difference-in-differences (DD) framework, in which $T$ denotes the treatment group affected by the tax reform, and $C$ is the control group. In the mean impact estimation we consider the pre-reform period 2004-2008 and limit the post-reform period to 2009-2011, given that an additional VAT reform was implemented in the restaurant sector on January 1, 2012, when the VAT rate was raised from 5.5 to 7 percent. The mean effect of the VAT reform on the outcomes of interest is estimated with the following unweighted regression: ${ }^{20}$

$$
\log Y_{i d t}=\eta \cdot \mathbb{1}\{i \in T\} \times \text { After }+\lambda_{t}+\omega_{i}+\epsilon_{i d t}
$$

where $i$ indexes the individual firm, $d$ indicates the département in which the firm is located, $t$ indexes the year in which the outcome is measured, After is a dummy variable equal to one in the post-reform period 2009-2011 and $Y$ represents each balance sheet item of interest (profits, cost of employees, cost of material goods etc.). ${ }^{21}$ In addition, the estimation model includes year fixed effects $\lambda_{t}$, which controls for differences across years shared by the treatment and control groups, and firm fixed effects $\omega_{i}$, which controls for firm characteristics that do not change over time. As a

\footnotetext{
${ }^{20}$ While weighting does change the magnitude of the estimated coefficients slightly, reducing the incidence of the tax on employees and firm owners, we believe that un-weighted estimates are preferable for our analysis. First they are more likely to reflect the average response of a firm in the economy. Given that 90 percent of sit-down restaurants have less than ten employees (and a within group average of 4 employees per firm) while the remaining 10 percent hires around 19 employees per firm, weighting by number of employees would increase the weight on the medium-sized and large firms. Second, very small firms are under-represented in AMADEUS, meaning that our estimates already assign higher weight to firms that are larger than the population average. Weighting by number of employees would exacerbate this problem.

${ }^{21}$ France is divided into 96 départements, which are administrative divisions whose land area covers around 2300 square miles on average, and median population around 500,000 in 2001, which is around 21 times the median population of a U.S. county.
} 
result, our identification strategy uses within firm variation across time once aggregate differences over time are controlled for. ${ }^{22}$

The error term $\epsilon_{i d t}$ is clustered by département to control for the possibility of within group correlation among firms located in the same geographical area. $\epsilon_{i d t}$ captures unobserved individual $\times$ département $\times$ year shocks to the outcome of interest. It is also assumed to be uncorrelated with the regressor of interest, so that

$$
E\left[\epsilon_{i d t} \times(\mathbb{1}\{i \in T\} \times \text { After }) \mid \lambda_{t}, \omega_{i}\right]=0
$$

is satisfied. While this identifying assumption is not directly testable in the data, it would be violated only if there were omitted factors that are not controlled by firm characteristics and that affect the treatment and control groups differentially over time.

Our preferred control group includes all non-restaurant firms operating in market services. The definition of market services follows the INSEE definition and includes services that are comparable to the restaurant industry because of their similar nature, but not directly substitutable with restaurants. $^{23}$ It includes wholesale and retail trade; repair of motor vehicles and motorcycles; accommodation service activities; information and communication; financial and insurance activities; real estate activities; professional, scientific and technical activities; and administrative and support service activities. It excludes sectors that are not traded on the market such as transportation, public administration activities, education, human health and social work activities as well as entertainment and recreation activities. ${ }^{24}$

\subsection{Estimates of Dynamic Effects}

The mean impact estimation defined above does not provide evidence on the dynamics of the adjustment in the outcomes we are interested in. We extend the previous analysis by assessing how quickly the variables we are interested in react to the change in the VAT, and how the impact evolves over time. This allows us to assess whether changes are long-lasting, and informs our

\footnotetext{
${ }^{22}$ In principle we could also include observable firm characteristics that change over time and across individual firms: legal status, the amount of fixed assets (tangible, intangible and other), the amount of current assets (stocks, debt and other), the amount of non-current assets (long-term debt and other) and current liabilities (loans, creditors and other) and the amount of shareholder funds (capital and other). In practice however they do not change the results substantially and may be mechanically correlated with the outcomes of interest.

${ }^{23}$ In principle one could restrict the set of services considered even further by only including services that are offered to consumers and not to corporations. This would for example exclude services like financial and insurance activities. Results do not change substantially if we narrow the control to only include consumer services.

${ }^{24}$ See data appendix for a detailed description of services included in the analysis.
} 
incidence analysis, which distinguishes between short-run, medium-run and long-run effects of the reform. In order to explore the dynamics, we augment our main model with leads and lags indicator variables and consider the period 2004-2012:

$$
\log Y_{i d t}=\sum_{\nu=-k}^{q} \eta_{\nu} \cdot \mathbb{1}\{i \in T\} \times \mathbb{1}\{t=\nu\}+\lambda_{t}+\omega_{i}+\epsilon_{i d t}
$$

where $\lambda_{t}$ capture shocks across years that are common to both the treatment and the control group. Given that we are controlling for time-invariant characteristics of the treatment group, not all the difference-in-difference coefficients are identified. For this reason, we normalize the coefficient on the event dummy in 2008 to be zero. The coefficients of interest $\eta_{\nu}$ deliver event-study like coefficients, and allow us to quantify the effect of the reform every year before and after it is implemented. It can be interpreted as the percent change in the outcome of interest in each given year relative to the pre-reform year assuming that, absent the tax change, the difference between treatment and control groups would have been the same as in 2008 .

\section{Results}

In this section we show evidence on aggregate prices around the time of the reform and discuss the evidence on both the average and dynamic effects of the VAT cut on the number of employees per firm, the cost of employees, the cost of material goods purchased and the return to sit-down restaurant owners.

Overall, our estimates suggest that the VAT reform caused a decrease in prices, as well as an increase in the cost of employees, the cost of materials purchased and the return to sit-down restaurant owners. We show that the reform had a small effect on the quantity of goods sold. In addition, as described below, the reform did not produce a statistically significant increase in employment: neither the number of employees hired by each firm nor the number of sit-down restaurants increased significantly around the time of the reform.

\subsection{Effect on Prices}

Our price analysis compares the price of sit-down meals to the price of non-restaurant market services. We observe a discontinuous drop in the price of sit-down meals at the time of the reform in July 2009. Panel a. of Figure 1 shows that it was small relative to the VAT cut. Prices dropped 
by around 1.3 percent in the first month after the reform, while the VAT cut amounted to 14.1 percent, implying a pass-through of 9.7 percent. ${ }^{25}$

Panel b. of Figure 1 shows the log-difference between the seasonally adjusted price of sit-down meals and the price of market services relative to June 2009. ${ }^{26}$ The Figure shows that, relative to the control group, the price of sit-down meals dropped by around 2.1 percent in the month after the reform, that the log-difference increased until the beginning of 2010, and that it started to decrease from then on to reach around 1.9 percent in December 2011. This evidence suggests that while the VAT cut had an immediate effect on prices using market services as a comparison, it was both small and temporary. ${ }^{27}$

We also use an alternative control group which, though not as desirable as non-restaurant market services, serves as a robustness check to our findings. Given that most sit-down restaurants are small firms with less than 10 employees, we consider all non-restaurant small firms as a second control group. In our sample, around 90 percent of sit-down restaurants are small firms, which is close to the aggregate data reported by the INSEE, according to which 86 percent of restaurants employ less than 10 workers. This second control group is not as close to sit-down restaurants as market services in terms of the nature of the activity, but is more comparable in terms of firm size. $^{28}$

While the pass-through of the VAT cut was low, the true effect on prices could have been even

\footnotetext{
${ }^{25}$ The small drop in prices following a VAT cut is consistent with the more general findings of Benzarti et al. (2017): the authors consider a large set of commodities across European countries over 20 years, and show that prices respond less to VAT decreases relative to VAT increases. The authors also show that the pass-through of the tax is especially small if one compares the 2009 reform to the 2012 and 2014 reforms, when the VAT rate on restaurants was raised from 5.5 to 7 percent and from 7 to 10 percent respectively. The pass-through to prices amounted to $49 \%$ for the 2012 reform, and 38 percent for the 2014 reform.

${ }^{26}$ We seasonally adjust the price series estimating monthly fixed effects for the period January 2004 to December 2011, and subtracting them to the non-seasonally adjusted series provided by both the INSEE and EUROSTAT. In the price data, market services include COICOP commodities that EUROSTAT classifies as services and that are produced in sectors that the INSEE classifies as non-restaurant market services. See the data appendix for more details on the list of services considered.

${ }^{27} \mathrm{~A}$ direct implication is that the before-tax producer price charged by restaurants increased considerably after the reform. If prices dropped by 2.1 percent, and the cost of materials had remained unchanged, both sales and value-added would have increased by 12 percent. In practice value-added increased by less than that because the cost of materials purchased by restaurants also went up in 2009.

${ }^{28}$ While other restaurants (which includes both cafes and other self-service catering (56.10B) and take-away restaurants $(56.10 \mathrm{C})$ ) would also seem at first glance to be an appealing control group because it has similar characteristics to the sit-down restaurants sector and was not affected by the VAT reform, we do not consider it in our analysis. First, from a consumer perspective, it is likely that sit-down restaurants and other restaurant services are highly substitutable. Therefore, when sales increase in one sector, they probably decrease in the other sector as consumers move from one to the other. Secondly, from a producer perspective, other restaurants might react to price changes in sit-down restaurants by adjusting their own prices in the same direction. This is consistent for example with the evidence in panel c. of Figure 1 and is likely to bias our difference-in-differences estimation downward. Finally, there is a large pre-trend in the difference between prices of sit-down restaurant meals and goods consumed in other restaurants.
} 
lower if sit-down restaurants had increased their prices in anticipation of the reform. This concern is shared by the study of Lafféter and Sillard (2014), which points out that prices increased at an unusually high rate in the months preceding the reform. Though this is a possibility, the increase in price observed for restaurants and hotels in the period January 2008-July 2009 was not specific to France but was also observed in other European countries, as reported in Lafféter and Sillard (2014). It is possible that this increase had been partly driven by the increase in the international price of food materials, which peaked in the middle of 2008 .

Furthermore, the change in VAT rate applied to sit-down restaurants was approved by the European Commission in January 2009, while the increasing price trend started at the beginning of 2008. It is therefore unlikely that the observed price increase was due to restaurant owners anticipating the reform. As shown in panel d. of Figure 1, a counterfactual price distribution which incorporated anticipatory effects in the months prior to the reform would lead to an even lower benefit of the VAT cut to consumers.

\subsection{Effect on Balance Sheet Items}

Table 2 shows the mean effect of the reform on balance sheet variables, estimated by specification (1). Column (1) of Table 2 shows that there was no effect on firm employment while column (2) of Table 2 shows that the cost per employee increased by 3.9 percent after the reform. ${ }^{29}$ Figure 3 uses equation (2) to estimate the dynamic effects of the reform and shows that there was no effect on number of employees (panel a.) and an increase in the cost of employees that lasts until 2012 (panel b.). The estimated coefficients displayed in Figure 3 confirm that the number of workers employed by each sit-down restaurant did not change significantly after the reform. Although the average number of employees in each given firm also did not change, a possible concern is that firms entered the market at the time of the reform, thereby increasing total employment: we do not find evidence of this pattern in our sample. ${ }^{30}$ We therefore conclude that the reform did not have a significant effect on employment, which is consistent with the fact that the output produced

\footnotetext{
${ }^{29}$ While the increase could have been due to either an increase in wages and salaries or an increase in the employer's share of payroll taxes on wages, we later show evidence supporting the conclusion that wages and salaries increased slightly after the reform. In addition, panel b. of Figure 3 shows that the effect on the average cost per employee is long-lasting. The Figure, which plots event-time coefficients for the period 2004-2012, shows that in the pre-reform period 2004-2008 the difference in the average cost per employee between sit-down restaurants and market services is zero relative to 2008, while it is positive and strongly significant in the years following the reform.

${ }^{30}$ See appendix Figure A.2. A limitation is that AMADEUS only records information on firms that are required to report to local tax authorities and misses information on small firms. Our results are therefore missing the potential positive effect on employment driven by unrecorded small sit-down restaurants increasing employment more than small firms offering non-restaurant market services.
} 
by sit-down restaurants also did not change significantly, as shown in Figure 2.

The reform had a positive effect on both profits and return to capital. Column (3) of Table 2 shows that the return to capital increased by around 10 percent in the post-reform period, while column (4) indicates that profits (which are one component of the return to capital) increased by 18 percent. ${ }^{31}$ The dynamic effects of the reform on the return to capital and profits are shown respectively in panel a. of Figure 4 and panel c. of Figure $3 .{ }^{32}$ Panel a. of Figure 4 shows that the return to capital increased by around 10 percent from 2008 to 2009, that it kept increasing in 2010, and that it started decreasing in 2011, perhaps because of increasing competitive pressures in the industry. Given the downward trend in the log-difference between the return to capital of sit-down restaurants and non-restaurant market services, we also show in panel c. of Figure 4 that taking into account this downward trend would lead to an even higher benefit of the VAT cut to restaurant owners.

Lastly, panel d. of Figure 3 shows that the VAT reform had an effect on the cost of material goods. This increase could be due to either an increase in the price of material goods: suppliers try to extract the rent generated by the VAT cut by increasing their prices. It could also be due to an increase in the "quantity" of material goods: while we find no effects on the volume of goods sold, it could be that restaurants are providing better quality meals or investing in improving their restaurant. ${ }^{33}$

Overall, the reduced-form evidence is consistent with sit-down restaurant owners being the main beneficiaries of the VAT cut. This finding is in contrast with the goals set by the Government directives contained in the Contrat d'Avenir, which demanded the VAT cut to be equally split between consumers, employees and restaurant owners. The results therefore raise questions on the effectiveness of non-binding government directives in significantly affecting firm price setting and hiring decisions.

\footnotetext{
${ }^{31}$ Given that the average profit-per-employee in 2008 was 2,500 euros, our findings suggest that total profits increased by about 2,250 euros for an average sit-down restaurants hiring 5 employees.

${ }^{32}$ Alternative measures of return to capital can be used. For example, one could exclude depreciation and interest payments from our measure of return to capital. In practice this does not substantially change our results. Panel b. of Figure 4 shows how our results change when using alternative measures of return to capital.

${ }^{33}$ In addition, an increase in the per-unit cost of inputs purchased might be due to reasons that are unrelated to the reform, such as an increase in the international price of the commodities used by restaurants. While this is unlikely to be the case for food commodities, which did not change dramatically throughout 2009, we cannot completely rule out this mechanism as we do not observe the exact composition of the inputs purchased.
} 


\section{$5 \quad$ Are Wages Really Higher?}

\subsection{No Increase In Hours Worked}

We show that the observed change in the cost per employee reflects an increase in the hourly wage rather than an increase in the number of hours worked. While hours worked per week are highly regulated in France, employees are allowed to work supplementary hours in an amount that varies with firm size, the nature of the business and the period of the year. The national legal limit on hours worked is 39 hours per week for restaurant employees, which is higher than the 35 hours per week in most of the other sectors of the economy. Supplementary hours are allowed with the condition that total hours do not exceed 48 per week. ${ }^{34}$ It is therefore possible that employees adjusted their hours worked after the reform, and that the increase in the average cost per employee observed is due to increased working hours rather than increased wages.

In order to test for this, we use survey data from the Enquete Emploi en Continu (EEC) and estimate dynamic effect coefficients for changes in hours worked using within region and across time variation in hours worked: ${ }^{35}$

$$
\log h_{\text {irt }}=\gamma \cdot \mathbb{1}\{i \in T\}+\sum_{\nu=-k}^{q} \delta_{\nu} \cdot \mathbb{1}\{i \in T\} \times \mathbb{1}\{t=\nu\}+X_{\text {irt }}+\lambda_{t}+\omega_{r}+\epsilon_{\text {irt }}
$$

where $h_{\text {irt }}$ is a measure of the labor intensity of individual $i$ employed in region $r$ in year $t$, the treatment group $T$ includes all employees of sit-down restaurants, $X_{\text {irt }}$ includes individual characteristics, $\lambda_{t}$ are year fixed effects, $\omega_{r}$ are region fixed effects, and standard errors are clustered by region. ${ }^{36}$ The outcome variables we focus on are self-reported measures of the number of hours worked during a reference week (both base and supplementary), as well as the average number of days worked in a given week. ${ }^{37}$ Table 3 and Figure 5 use specification (3) to show that there was no statistically significant response in the number of hours and days worked.

\footnotetext{
${ }^{34} 60$ hours per week are allowed under very specific circumstances.

${ }^{35}$ France is divided into 27 administrative regions, which are larger than départements, and are the most detailed geographic information contained in the EEC data.

${ }^{36}$ We include age, gender, education, tenure, occupation, marital status, number of employed workers, number of unmarried children living in the household, establishment size, firm size, birth region, and quarter in which worker was surveyed.

${ }^{37}$ Considering alternative definitions of hours worked such as the number of hours normally worked in a given week or the number of hours corresponding to the salary declared in the survey does not change the results.
} 


\subsection{The Effect of the Payroll Subsidy Cut}

So far, we have interpreted the post-reform increase in the cost per employee as an increase in wages and salaries rather than an increase in payroll taxes. In this section we substantiate this claim by showing that the payroll subsidy cut that took place in July 2009, at the same time the VAT cut was implemented, had limited effect on the cost per employee. All restaurants and hotels had been eligible for a monthly payroll subsidy for each employee hired since 2004, and the amount varied based on the employee's wage and the tenure of the firm. ${ }^{38}$ This payroll subsidy expired in July 2009, raising the cost of employees hired by restaurants and hotels.

The effect of the removal of the payroll subsidy is likely to be limited compared to the VAT cut because the payroll subsidy granted to hotels and restaurants was substantially smaller than the 2009 VAT cut. Payroll subsidies were at most 1,368 euros per employee per year, while the VAT cut was a 14.1 percent reduction in the tax on total value-added. Given that the average value-added in our sample is around 300,000 euros, and that each sit-down restaurants hires around 5.5 employees, it follows that on average the VAT cut resulted in savings of around 7,500 euros per employee per year.

In order to take into account this additional effect on the cost of employees we compare the evolution of the cost of employees in the hotel industry, which was affected by the subsidy cut but not the VAT cut, to that of the same outcome in non-restaurant market services, which was not affected by the subsidy cut nor the VAT cut.

Our treatment group includes three sub-sectors of the hotel industry: (a) hotels and similar accommodation, (b) holiday and other short-stay accommodation and (c) camping grounds and recreational vehicle parks. We denote the treatment group by $S C$ and compare it to firms in market services by estimating:

$$
\log Y_{i d t}=\alpha \cdot \mathbb{1}\{i \in S C\} \times \text { After }+\lambda_{t}+\omega_{i}+\epsilon_{i d t}
$$

where $\lambda_{t}$ are year fixed effects, $\omega_{i}$ are firm fixed effects and $\alpha$ measures the change in the outcome variable $Y$ in the period 2009-2011 when one compares the hotel industry to non-restaurant market services. Table 4 shows that removing the hiring subsidy had a negative effect on employment, while having a positive effect on the remaining variables. We use the estimated $\alpha$ for each of the outcome variables and subtract them from the coefficients in our main estimates, which includes both the

\footnotetext{
${ }^{38}$ See appendix section 3 for details on the payroll subsidy program.
} 
effect of the VAT cut and the effect of the payroll subsidy cut. We report these deflated eventtype coefficients in Figure 6. We find that - holding constant the payroll subsidy - the effect of the VAT cut on cost per employee, return to capital and cost of materials are similar to the ones reported using our main specification. However, had the payroll subsidy been in place, we would have observed an increase in the number of employees caused by the VAT cut. Therefore, the reason why we observe no increase in hiring following the VAT cut is due to the removal of the payroll subsidy.

\subsection{Restaurant Owners Have No Tax Incentive to Reclassify Profits as Wages}

It is also unlikely that the cost per employee increased as a result of sit-down restaurant owners paying higher wages to themselves. This is unlikely because restaurant owners in France are primarily self-employed, and it is more beneficial for self-employed individuals to declare income in the form of profits, an incentive that the VAT cut did not change. Restaurants in France are considered part of the artisants, commercants et industriels (craftsmen and traders) sector and are subject to a specific tax regime, under which the tax on firm owners is lower than the tax on employees. Profits in this sector, from which firm owners pay themselves, are called revenue mixte by the fiscal authority and are treated as a mix of wage and profit income. The revenue mixte is subject to a sum of income tax and an artisants, commercants et industriels specific payroll tax rate, which is lower than the regular payroll tax rate paid by employees because firm owners do not contribute to (and are therefore not eligible for) unemployment insurance. Hence reducing firm profits to increase wages and salaries would not be beneficial from a tax perspective. We therefore conclude that, even if small restaurants were managed by several individuals - some of whom could be family members hired as employees - it is unlikely that firm owners reclassified value-added from profits to wages.

\section{Welfare Analysis}

\subsection{Theory}

In this section we build on the theoretical framework of Auerbach and Hines (2002) and develop a formula that allows us to empirically estimate the share of the consumption tax falling on consumers, employees, firm owners and sellers of material goods. The framework defined in Auerbach and Hines (2002) shows that while the marginal excess burden created by an increase in consumption taxes can 
be of first order significance if a tax is already in place, the first order welfare effect of the tax is given by the change in the revenue collected keeping quantities fixed and is a reasonable approximation for the total welfare effect of the tax. ${ }^{39}$ This framework offers a reasonable approximation of the incidence of the reform we consider in this paper given that, as documented above, the reform did not have large effect on output and employment in the restaurant industry.

Figure 7 illustrates the effect of a VAT cut on consumers. In order to build intuition, we consider the scenario in which prices faced by consumers decrease by exactly the amount of the tax change, that is $p_{1}=p_{0}+\Delta \tau$. The change in total revenue produced by the tax equals $A$ - $D$, with $A$ being the loss in revenue on the quantity sold before the reform, and $D$ being the revenue collected on the additional units sold as the tax is lowered. Given that the deadweight loss decreases by $C+D$ with the tax cut, the overall welfare effect of the tax equals $A+C$, where $A$ is first-order and $C$ is second-order. In our analysis, we are assigning shares of the first order welfare effect of the $\operatorname{tax} A$ to consumers, employees, firm owners, and sellers of material goods. If, as it is the case in Figure 7 , the price cut observed after the reform equals the pre-reform price plus the tax change $\left(p_{1}=p_{0}+\Delta \tau\right)$, then consumers are the only beneficiaries of the tax cut, because the change in tax revenue (holding quantities fixed) corresponds to the first order effect of the tax on consumers. If instead $p_{1}>p_{0}+\Delta \tau\left(p_{1}<p_{0}+\Delta \tau\right)$, then the effect on consumers is smaller (larger) than the change in tax revenue, and some of the tax cut is distributed to (paid by) employees, sellers of material goods and firm owners through changes in wages $\left(w_{x}\right)$, per-unit cost of material goods $\left(c_{x}\right)$ and the return to capital $\left(r_{x}\right)$. In a perfectly competitive market, the value of output is distributed between capital, labor and sellers of material goods. Using the envelope theorem we have that:

$$
(1-\tau) p_{x} d X=w_{x} d L_{x}+(1-\tau) c_{x} d M_{x}+r_{x} d K_{x}
$$

and therefore ignore changes in quantities produced by the tax cut. The first order welfare effect of the tax is thus given by the sum of the extra revenue collected on the pre-reform value-added and the extra revenue collected from the increase in value-added produced by the change in the price

\footnotetext{
${ }^{39}$ While the framework defined in Auerbach and Hines (2002) is mostly suited to studying differential changes in taxes and prices, the change in revenue keeping quantities fixed is a better approximation of the total welfare effect of the tax than the change in the total revenue collected after the tax change, which would include the extra revenue raised on the units sold previous to the tax change and the revenue loss from the decrease in quantity sold.
} 
of output and material goods:

$$
d \tau\left[X p_{x}-c_{x} M_{x}\right]+\tau\left[X d p_{x}-M_{x} d c_{x}\right]=X d p_{x}+L_{x}\left(-d w_{x}\right)+K_{x}\left(-d r_{x}\right)+M_{x}\left(-d c_{x}\right)
$$

It follows that the burden of the tax on consumers, employees, capital owners and sellers of material goods can be decomposed as:

$$
\begin{aligned}
& \underbrace{\frac{d \ln p_{x}}{d \tau(1-\delta)+\tau\left(d \ln p_{x}-\delta d \ln c_{x}\right)}}_{\text {Share on Consumers }}-\underbrace{\frac{d \ln w_{x}}{d \tau(1-\delta)+\tau\left(d \ln p_{x}-\delta d \ln c_{x}\right)}}_{\text {Share on Employees }} \\
& -\underbrace{(1-\gamma-\delta) \frac{d \ln r_{x}}{d \tau(1-\delta)+\tau\left(d \ln p_{x}-\delta d \ln c_{x}\right)}}_{\text {Share on Capital Owners }}-\underbrace{\delta \frac{d \ln c_{x}}{d \tau(1-\delta)+\tau\left(d \ln p_{x}-\delta d \ln c_{x}\right)}}_{\text {Share on Sellers of Material Goods }}=1
\end{aligned}
$$

In this formula, each term is divided by the first order welfare effect of the tax on value-added, and the sum of the incidence shares is guaranteed to sum to one. While for example firm owners might also be consumers of the taxed good, this simple framework is useful to separate the incidence of the tax on the different groups, keeping everything else equal. If a firm owner is also a consumer, then the overall incidence on that individual takes into account both the incidence on consumers and the incidence on firm owners.

\subsection{Results}

In this section we use the reduced form estimates and the formula derived above to compute the incidence of the VAT reform on consumers, employees, sellers of material goods and firm owners. Figure 8 shows our incidence estimates, and focus on three time horizons, which correspond to the normal firms' balance sheet closing dates (December of 2009, 2010 and 2011). These three time horizons help create an overlap between firm balance sheet information, which is recorded only once a year, and the monthly price data. We denote the short-run as 6 months after the reform (December 2009), the medium-run as 18 months after the reform (December 2010), and the longrun as 30 months after the reform (December 2011). December 2011 is a reasonable choice for our longest time horizon because a new VAT reform was implemented on January 1st 2012, when the VAT rate on all restaurants was raised from 5.5 to 7 percent.

To implement equation (5) empirically we need information on the percent changes in $p_{x}, w_{x}$, $c_{x}$ and $r_{x}$, as well as the sales share going to consumers, employees, sellers of material goods and 
firm owners. Therefore we use the $\eta_{\nu}$ 's from Table 2 estimated in the reduced form analysis to approximate $d \ln w_{x}, d \ln r_{x}$ and $d \ln c_{x}$, and the log-differences in prices shown in panel b. of Figure 1 as an estimate for $d \ln p_{x} \cdot{ }^{40}$

We divide each firm's cost of employees, cost of material goods and return to capital by its total sales, and compute the average share of sales revenue going to workers $(\widehat{\gamma})$, sellers of material goods $(\widehat{\delta})$ and capital owners $(1 \widehat{-\gamma-} \delta)$ in the pre-reform year 2008. For instance, the share of income going to employed workers is estimated as:

$$
\widehat{\gamma}=\sum_{j=1}^{J} \gamma_{j}=\sum_{j=1}^{J} \frac{\text { Cost of Employees }}{j}
$$

Given that return to capital is total sales minus the cost of employees and materials, this guarantees that a firm's sales are split between firm owners, employees and sellers of material goods. Empirically, we find that $\widehat{\gamma}=0.39, \widehat{\delta}=0.32$ and $(\widehat{1-\gamma}-\delta)=0.29$.

Finally, we approximate the denominator of equation (5) with the sum of the numerators, so that the shares sum to one. In general, this approximation is reasonable if the reform does not produce large changes in quantities but mainly affect output and input prices. We show in Table 6 that in the case of the particular reform we analyze the approximation error is not very large. Besides changes in quantities, in our case the error might also reflects the fact that (1) we are combining national prices with firm-level balance-sheet information and (2) equation (5) is better suited for small changes in taxes, while in our scenario we consider a large VAT cut.

Short-Run Incidence The short-run incidence of the reform is measured in December 2009, six months after the reform. Panel a. of Table 5 shows that the VAT cut increased the return to capital by 9.8 percent between June and December 2009. While the number of employees did not change significantly with the reform, Table 5 shows that the cost of employees and the cost of materials both increased 6 months after the VAT reform, but less than the return to capital. On average, the cost of employees went up by 1.5 percent and the cost of materials increased by 3.8 percent. These estimates, which are weighted by the 2008 sales share as explained in the previous subsection, imply that the VAT cut largely benefited sit-down restaurant owners. Panel a. of Table 5 shows that 41.4 percent of the incidence was on restaurant owners, as opposed to 8.6 on employees and 17.1

\footnotetext{
${ }^{40}$ In the appendix of the paper we also show incidence estimates under two alternative scenarios. First, the first three columns of Table 7 shows the incidence under the counterfactual price series displayed in panel d. of Figure 1. Second, the last three columns of Table 7 shows the incidence using the counterfactual change in the return to capital displayed in panel c. of Figure 4 using a linear fit of the pre-reform years 2004-2008.
} 
on sellers of material goods.

Surprisingly our estimates also suggest that 32.9 percent of the short-run incidence of the tax fell on consumers, as displayed by the green area in Figure 8. There is one main reason why this result is likely an upper bound of the incidence on consumers. Our analysis combines national price data with balance sheet information from a subset of firms sampled in the AMADEUS data: if the price reaction of the firms not sampled in AMADEUS is smaller than that of the firms we consider, then our estimated incidence on consumers is larger than it is in the population. While we would need firm-level price data to address this point fully, smaller firms being less likely to cut prices is consistent with the evidence provided by Harju et al. (2017).

Medium-Run Incidence The medium-run impact of the reform reflects the effect of the tax 18 months after the reform, in December 2010. Panel b. of Table 5 shows that the cost of employees increased by 4.7 percent relative to 2008, a larger increase if compared to the short-run effect reported in panel a. of the same Table. On the other hand, the percent change in the cost of materials in the medium-run is comparable to the one estimated in the short-run. In addition, panel b. of Table 5 shows that firm owners are again the main beneficiaries of the tax cut while the benefit to consumers is smaller in the medium-run than it was in the short-run. The lower incidence on consumers relates to the medium-run increase in the price of sit-down meals, as shown in Figure 1. Our results for the medium-run incidence on consumers are comparable to what Lafféter and Sillard (2014) find 18 months after the same reform. ${ }^{41}$

On the whole, sit-down restaurant owners share 47 of the benefit from the VAT cut in the medium-run, as shown by the red area in Figure 8. The share of the VAT cut going to employees (17.7 percent) is higher 18 months after the reform than it was 6 months after the reform, likely because wages take some time to adjust, while the share of the VAT cut going to sellers of material goods (11.8 percent) and consumers (23.5 percent) decreases in the medium-run relative to the short-run.

Long-Run Incidence Panel c. of Table 5 shows that in the long-run, which we define as December 2011 (two and a half years after the VAT cut), the share of the burden on employees and sellers of material goods increased to 24.5 percent and 15.7 percent respectively. This is consistent

\footnotetext{
${ }^{41}$ In their study they compare the price of sit-down meals and other goods to the price of control groups that are different from ours. Their control groups are the price of goods in other sub-sectors of the restaurant industry, the price of sit-down restaurants in Italy, and a composite price index. In addition, they assume that with full pass-through, prices would decrease by 11.8 percent $\left(\frac{d t}{(1+t)}=\frac{0.141}{1.196}=11.8 \%\right)$ rather than 14.1 percent.
} 
with lower wage rigidities and with sit-down restaurants purchasing larger amounts of intermediate goods (or higher quality inputs) in response to changes in demand. On the other hand, and as a result of the price of sit-down restaurant meals increasing relative to the price of other services in the economy, the benefit to consumers further decreases (to 18.6 percent) in the long-run. Finally, as was the case for both our short- and medium-run estimates, sit-down restaurant owners are still the main beneficiaries of the VAT cut 18 months after the reform. This is shown in both Figure 8 and Table 5: we estimate that 41.2 percent of the incidence of the VAT cut in the long-run is on sit-down restaurant owners.

Incidence using Counterfactual Distributions As mentioned in a previous section of the paper, prices of sit-down restaurant meals increased in the months preceding the reform, likely because of an increase in the price of international price of food materials. If one interpreted this increase as an anticipatory effect, a counterfactual price series could be constructed, as shown in panel d. of Figure 1. If this counterfactual price series was used, the benefit of the VAT cut on consumers would be even lower and the benefit to restaurant owners would be larger. Our incidence estimates are shown in the first three columns of Table 7. We show that in this case only 17 percent of the VAT cut would go to consumers in the medium-run and 11.7 percent in the long-run.

In addition, the log-difference in the return to capital between sit-down restaurants and nonrestaurant market services had a downward trend in the years preceding the reform. If we used a line to fit this downward trend, as shown in in panel c. of Figure 4, the benefit on restaurant owners would be even larger. Our incidence results using this counterfactual log-difference are reported in the last three columns of Table 7. In this case 52.6 percent of the VAT cut would go to restaurant owners in the medium-run and 50 percent in the long-run.

\section{Robustness Checks}

Changes in Local Economic Conditions In principle the effects we identify could be driven by changes in local economic conditions that are different for the treatment and control groups. We therefore add a control for the département unemployment rate:

$$
\log Y_{i d t}=\eta \cdot \mathbb{1}\{i \in T\} \times \text { After }+\gamma \cdot \text { URate }_{d t}+\lambda_{t}+\omega_{i}+\epsilon_{i d t}
$$


For this purpose we use INSEE data on quarterly unemployment rates by département and compute the average unemployment rate by département in each given year. Table 8 shows that the results of our main analysis are robust to controlling for local unemployment rate. The estimated coefficients are comparable to the ones we get in our main specification, which are reported in Table 2 .

Alternative Control Group The results of the main analysis are also robust to using an alternative control group. Table 9 considers non-restaurant small firms as a control group and shows that the estimated mean impact of the reform is comparable to what we found in our main analysis, with the exception of the effect on the number of employees.

Column (1) of Table 9 shows that the effect on the number of employees is positive and statistically significant. Though this result would seem to undermine the accuracy of the coefficients estimated in our main analysis, the positive coefficient is unlikely to be driven by the reform. Importantly, panel a. of Figure 9 shows a positive trend even in years preceding the reform, which suggests that the average size of sit-down restaurants has increased over time.

The remaining coefficients reported in Table 9 are very similar to the ones found in the main analysis. Column (2) shows that the cost per employee increased by 3.8 percent, whereas column (3) and (4) show that the coefficients for return to capital and profits increased by 11 and 20 percent respectively. Finally, the cost of material goods purchased also increased, though by a slightly lower amount than estimated in the main analysis.

The causal effect on prices (shown in Figure A.3) is hard to interpret in this case, given the positive trend in the pre-reform years, but the log-difference in prices between the treatment and control group in the post-reform years is similar to what we found when using our main control group. ${ }^{42}$ Figure 9 shows dynamic effect coefficients when using non-restaurant small firms as a control group: the evidence is comparable to the findings of our main analysis, suggesting that our main estimates are robust.

Full Sample The main analysis of this paper uses a sample of firms with information on the number of employees. The main advantage of restricting the sample this way is that we can

\footnotetext{
${ }^{42}$ Non-restaurant prices are computed from Eurostat data, taking the national price index excluding energy prices $p_{a l l}$, the restaurant prices $p_{\text {rest }}$ and weights $w_{\text {rest }}$, and computing:

$$
p_{\text {non-rest }}=\frac{p_{\text {all } 100-p_{\text {rest }} w_{\text {rest }}}}{100-w_{\text {rest }}}
$$

The limitation of this measure is that it reflects the price charged by all rather than just small non-restaurant firms, for which we do not have specific information.
} 
separate the effect of the reform on wages and salaries from changes in employment. While this helps the interpretation of our results, it comes at the cost of reducing the sample size by half.

Figure A.4 shows event-time Figures estimated using the whole sample, when non-restaurant market services are used as a control group. The Figure shows that the reform had a positive and statistically significant effect on all the outcomes considered, as in our main analysis.

\section{Conclusion}

In this paper, we consider a large VAT cut in France and estimate the share of incidence that falls on consumers, employees, sellers of material goods and sit-down restaurant owners. Differently from previous papers in the literature, our results provide important insights on the distributional effects of consumption tax cuts, taking into account the effect on employees and sellers of material goods.

Our results show that prices had only decreased by 2 percent thirty months after the VAT cut, that the cost of employees and material goods increased by 3.9 and 4.4 percent respectively, and that the return to sit-down restaurants owners increased by around 10 percent. Using these reduced-form estimates we conduct a welfare analysis and find that : (1) the effect on consumers was limited, (2) employees and sellers of material goods shared 25 and 16 percent of the total benefit, and (3) the reform mostly benefited owners of sit-down restaurants.

\section{References}

Auerbach, A. J. and J. R. Hines (2002). Taxation and economic efficiency. Handbook of public economics 3, 1347-1421.

Benzarti, Y., D. Carloni, J. Harju, and T. Kosonen (2017). What goes up may not come down: asymmetric incidence of value-added taxes. Available at SSRN.

Carbonnier, C. (2007). Who pays sales taxes? evidence from french vat reforms, 1987-1999. Journal of Public Economics 91(5), 1219-1229.

Carbonnier, C. (2008). Différence des ajustements de prix à des hausses ou baisses des taux de la tva: un examen empirique à partir des réformes françaises de 1995 et 2000. Économie et statistique 413(1), 3-20.

Chouinard, H. and J. M. Perloff (2004). Incidence of federal and state gasoline taxes. Economics Letters 83(1), 55-60.

Consales, G., M. Fesseau, and V. Passeron (2009). La consommation des ménages depuis cinquante ans. Cinquante ans de consommation en France. 
Doyle, J. J. and K. Samphantharak (2008). $\$ 2.00$ gas! studying the effects of a gas tax moratorium. Journal of Public Economics 92(3), 869-884.

FAFIH (2011). Portrait sectoriel, l'observatoire de l'hôtellerie et la restauration.

Fougère, D., E. Gautier, and H. Le Bihan (2010). Restaurant prices and the minimum wage. Journal of Money, Credit and Banking 42(7), 1199-1234.

Gruber, J. and B. Köszegi (2004). Tax incidence when individuals are time-inconsistent: the case of cigarette excise taxes. Journal of Public Economics 88(9), 1959-1987.

Hanson, A. and R. Sullivan (2009). The incidence of tobacco taxation: evidence from geographic micro-level data. National Tax Journal, 677-698.

Harju, J., T. Kosonen, and O. Nordström Skans (2017). Firm types, price-setting strategies, and consumption-tax incidence. Labor Institute for Economic Research Working Papers (70).

Hines, J. and M. Desai (2005). Value-added taxes and international trades: the evidence. Working Paper.

Houel, M. (2010). Bilan du taux réduit de tva dans le secteur de la restauration. Rapport d'information, Sénat.

Kenkel, D. S. (2005). Are alcohol tax hikes fully passed through to prices? evidence from alaska. American Economic Review, 273-277.

Kopczuk, W., J. Marion, E. Muehlegger, and J. Slemrod (2013). Do the laws of tax incidence hold? point of collection and the pass-through of state diesel taxes.

Kosonen, T. (2015). More and cheaper haircuts after vat cut? on the efficiency and incidence of service sector consumption taxes. Journal of Public Economics 131, 87-100.

Lafféter, Q. and P. Sillard (2014). L'addition est-elle moins salée ? la réponse des prix à la baisse de tva dans la restauration en france. Technical Report F1404.

Naritomi, J. (2013). Consumers as tax auditors. Working Paper.

Pomeranz, D. (2015). No taxation without information: Deterrence and self-enforcement in the value added tax. The American Economic Review 105(8), 2539-2569.

Seguin, S. (2011). Les bénéficiaires de la revalorisation du smic et des garantes mensuelles au 1er juillet 2004 .

Slemrod, J. (2011). Does a VAT promote exports? Tax Analysts, 186-91. 
Figure 1: Effect of VAT Cut on Prices

a. Actual vs. Full Pass-Through

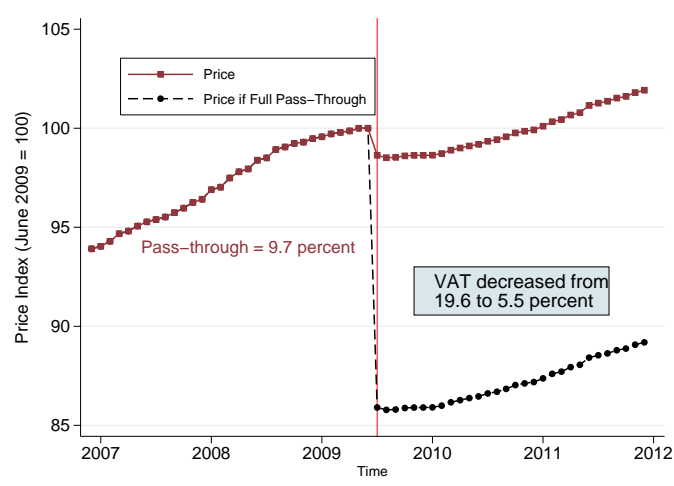

c. Price Level in France

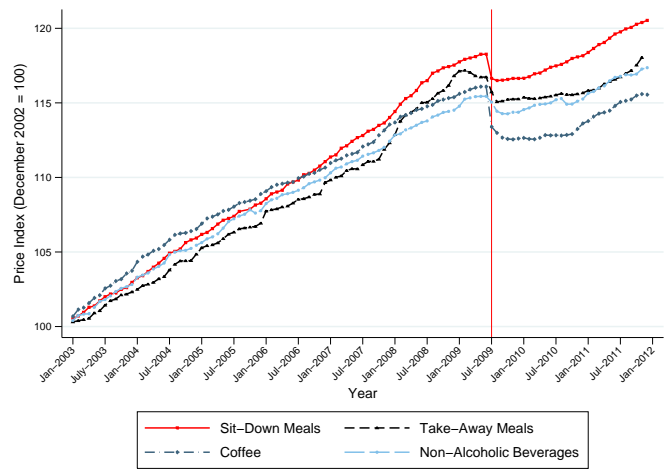

b. Log-Difference in Prices

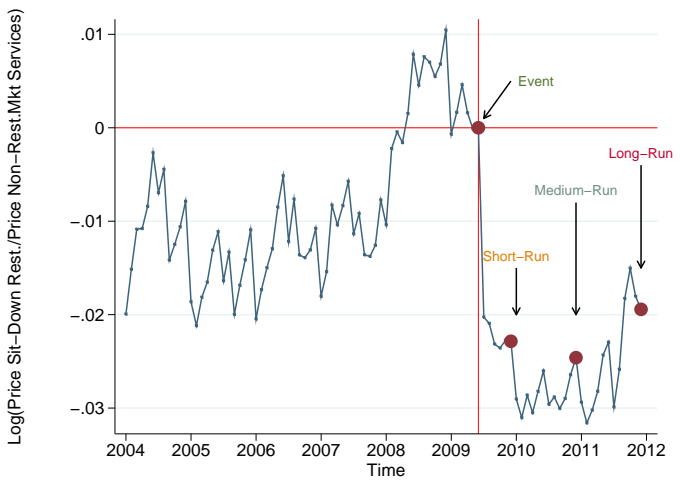

d. Counterfactual Price Difference

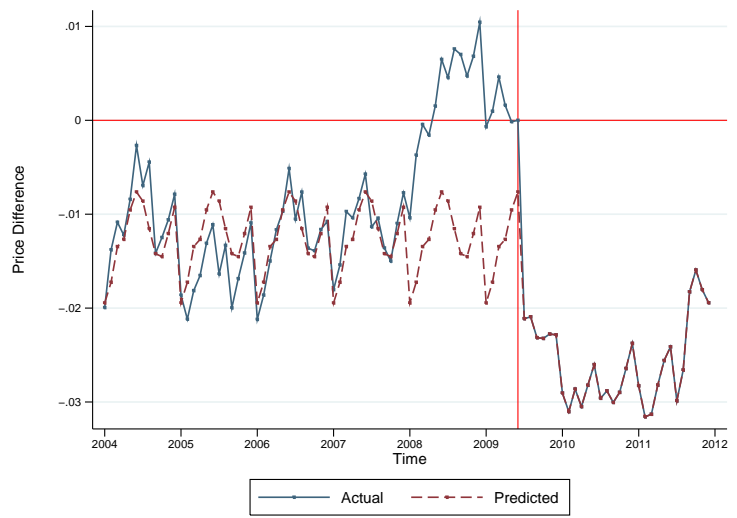

Source: In panel a. the price with full pass-through is computed assuming that its percent change is equal to the level difference in the VAT rate, which decreased from 19.6 to 5.5 percent. Panel b. uses INSEE data and authors' computations on Eurostat data. The price of nonrestaurant market services uses Eurostat price data and is computed as a weighted average (using EUROSTAT weights) of seasonally adjusted prices by four digits COICOP. Price series are seasonally adjusted using monthly dummies. The Figure in panel c. is constructed using Eurostat and INSEE data. Panel $d$. shows the same price series as panel $b$ and computes a counterfactual price difference, constructed from fitting the price change in the period January 2004-December 2007 on an eighth order polynomial of the month variable. 
Figure 2: Effect of VAT Cut on Quantities

a. Sit-Down Restaurants, Value

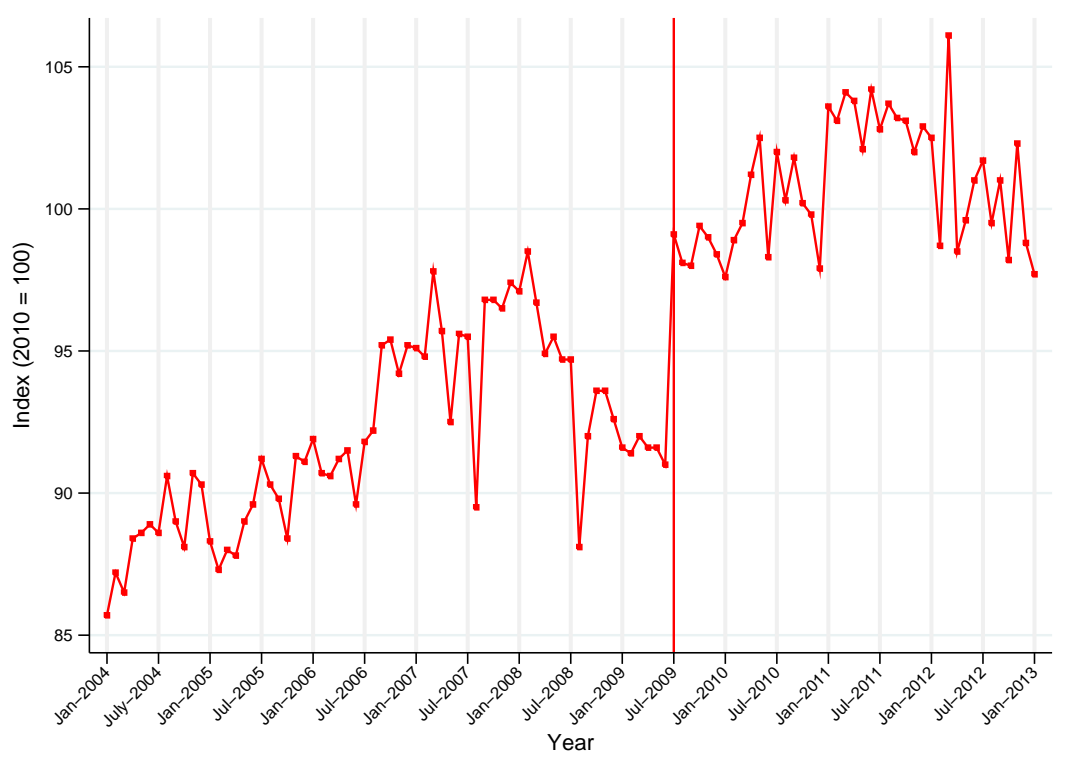

b. Sit-Down Restaurants, Volume

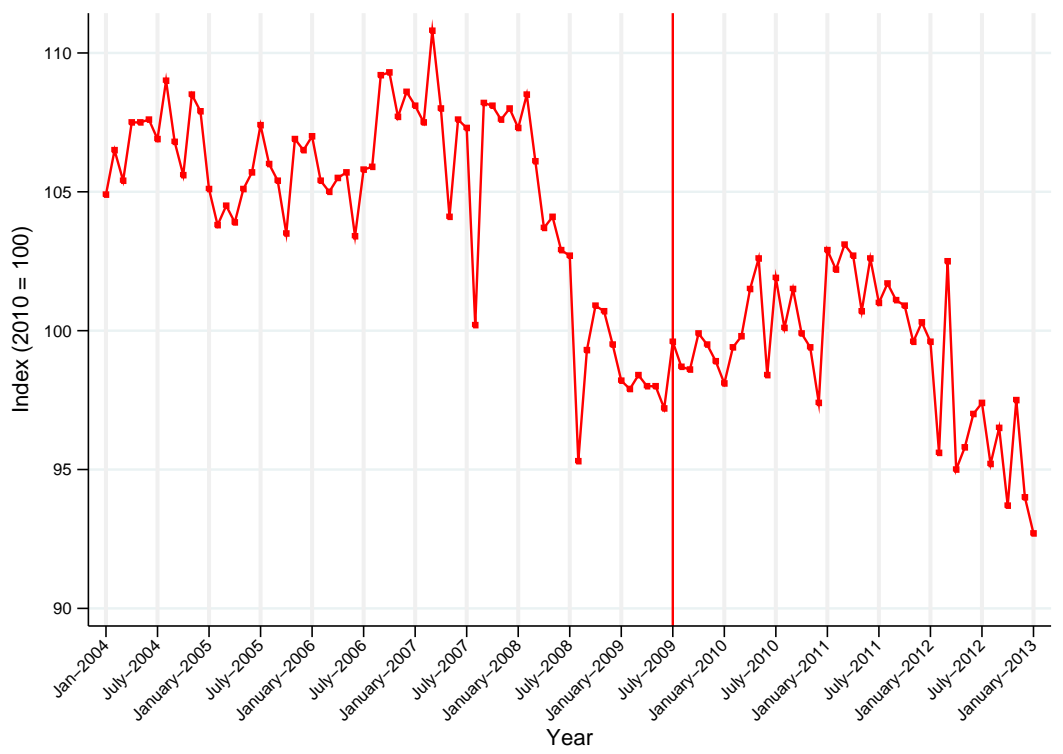

Source: The Figures show aggregate INSEE data on value and volume of goods sold by sitdown restaurants. 
Figure 3: Dynamic Effects of the VAT Cut: Sit-Down Restaurants vs. Market Services

a. Number of Employees

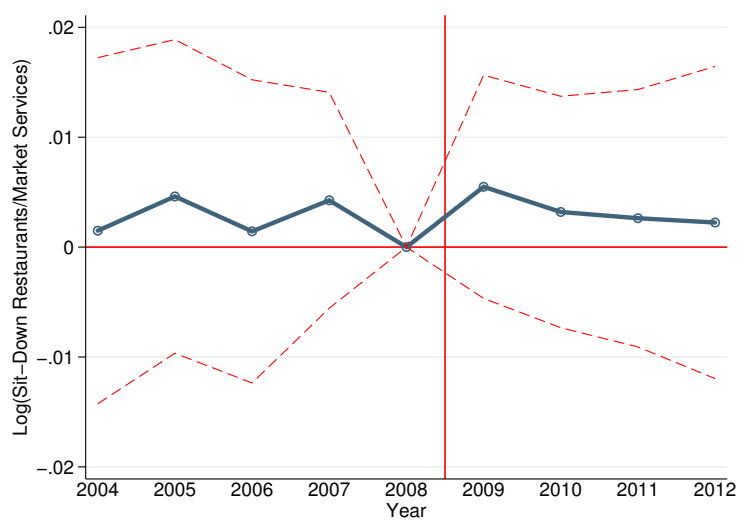

c. Profits

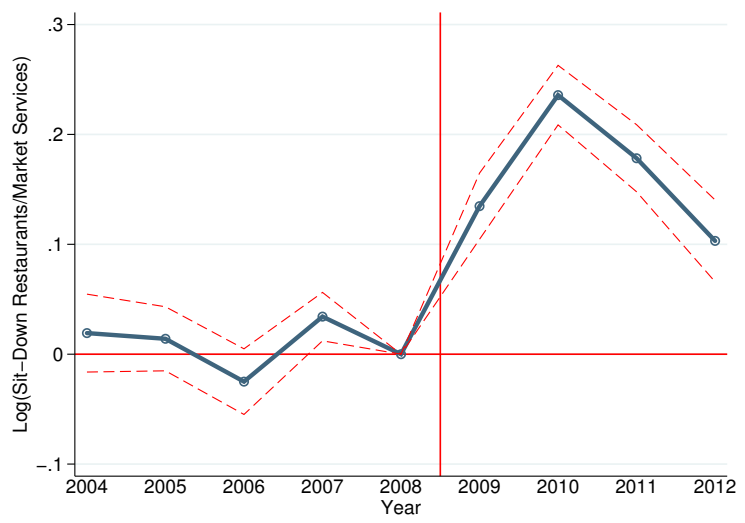

b. Cost of Employees

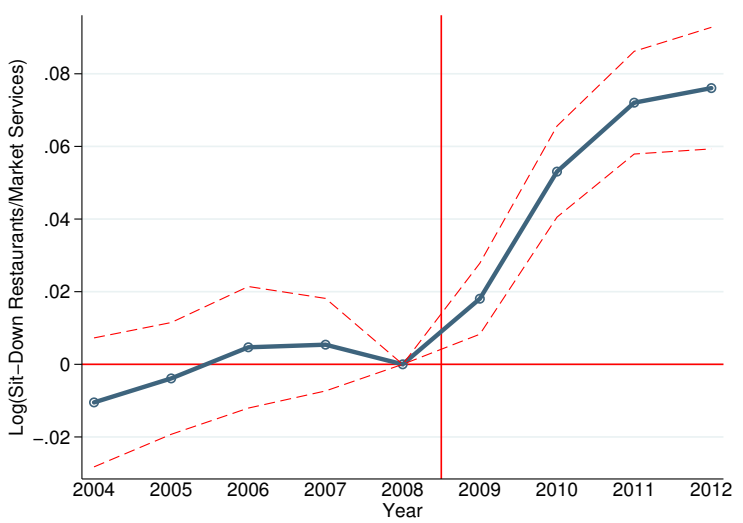

d. Cost of Material Goods

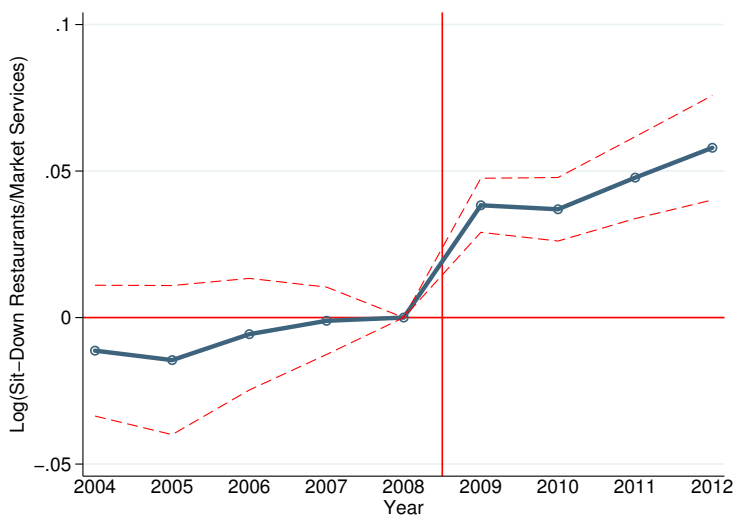

Notes: The Figure shows event-time coefficients estimated using equation (2), which includes year and firm fixed effects. The treatment group includes all sit-down restaurants, while the control group includes all firms in non-restaurant market service sectors. The dashed lines represent 95 percent confidence intervals. 
Figure 4: Dynamic Effects of the VAT Cut: Sit-Down Restaurants vs. Market Services (continued)

a. Return to Capital

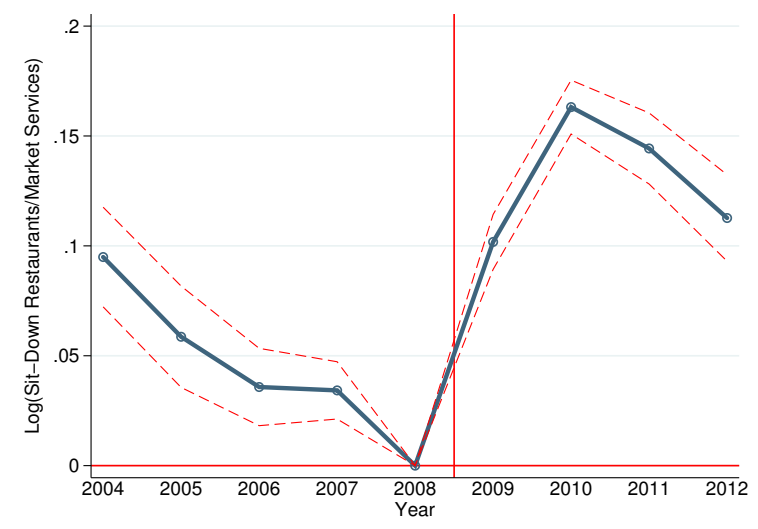

c. Counterfactual Return to Capital

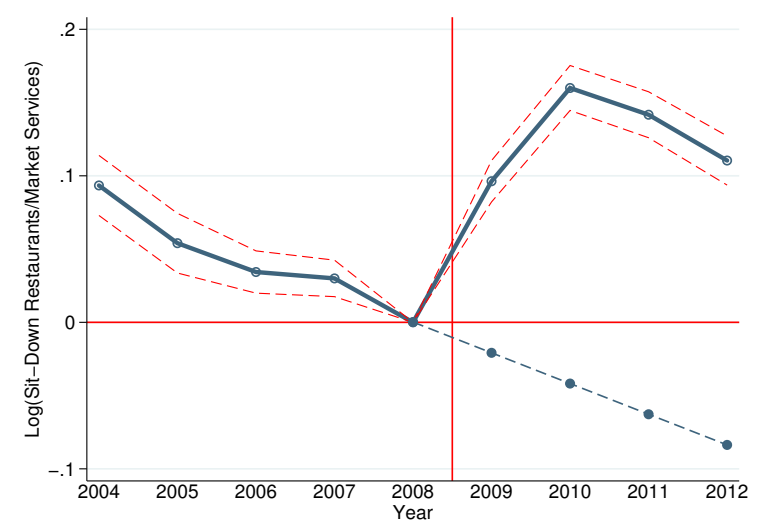

b. Alternative Measures of Return to Capital

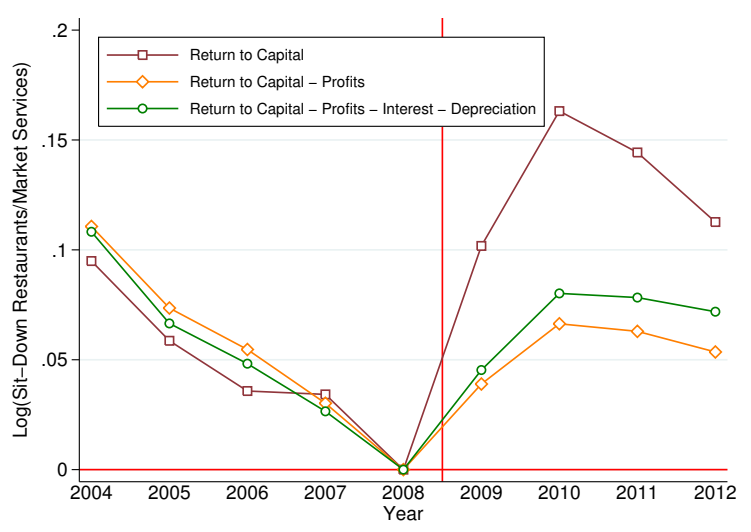

Notes: Panel a. and b. show the dynamic effects of the reform estimated using equation (2), which includes year and firm fixed effects. The treatment group includes all sit-down restaurants, while the control group includes all firms in non-restaurant market service sectors. The dashed lines represent 95 percent confidence intervals. Panel c. shows the dynamic effects of the reform estimated using equation (2). The counterfactual log-difference is constructed using a linear fit on the pre-reform years 2004-2008. The treatment group includes all sitdown restaurants, while the control group includes all firms in non-restaurant market service sectors. The dashed lines represent 95 percent confidence intervals. 
Figure 5: Hours Worked during Reference Week: Event-Time Estimates

a. Base Hours

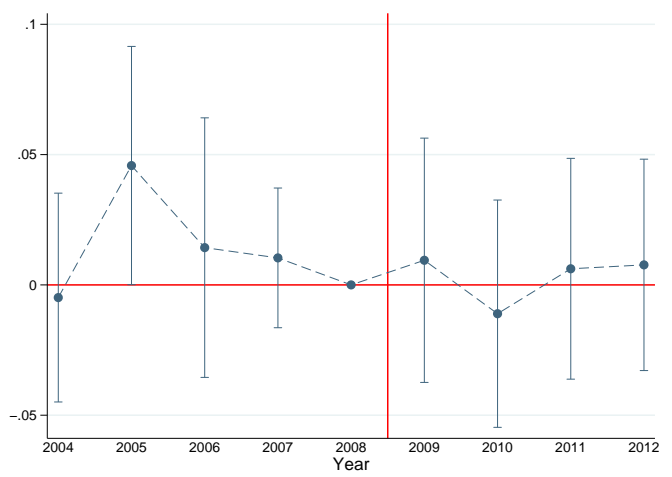

c. Total Hours

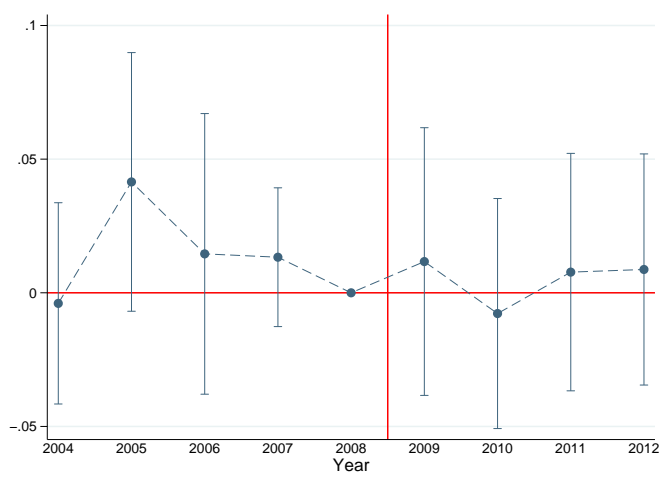

b. Supplementary Hours

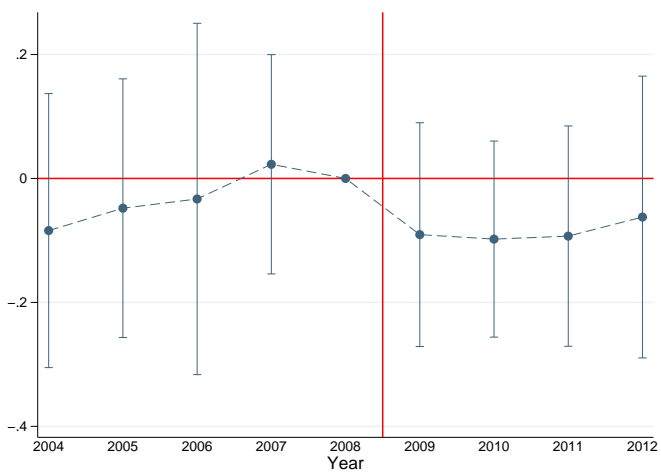

d. Days Worked

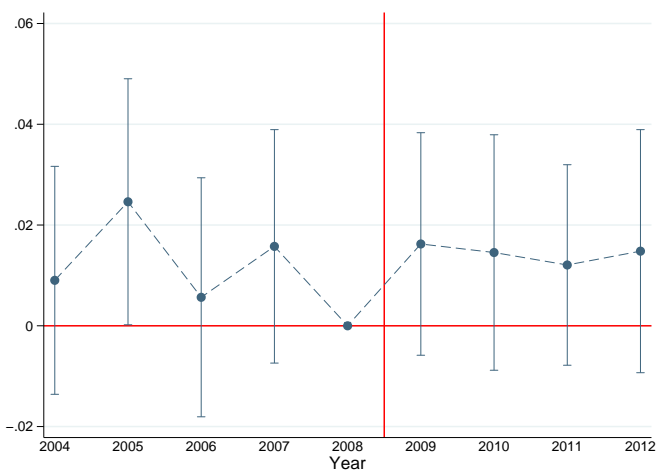

Notes: Event-type coefficients computed using equation (3). The treatment group includes employees of French sit-down restaurants, while the control group includes employees of nonrestaurant market service sectors. 
Figure 6: Deflated Coefficients: Sit-Down Restaurants vs. Market Services

a. Number of Employees

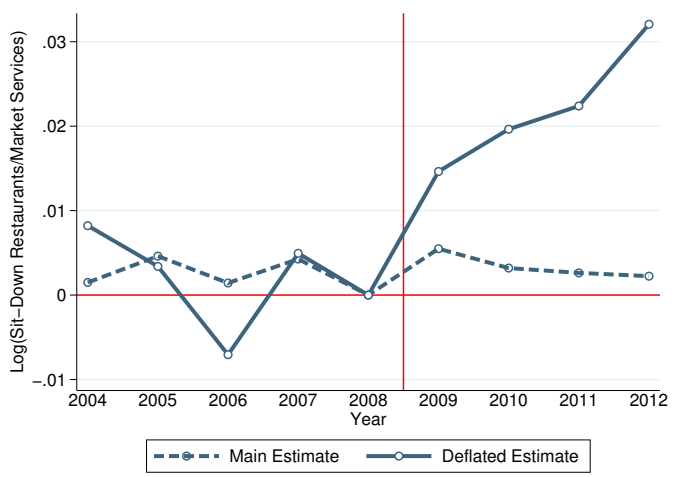

c. Return to Capital

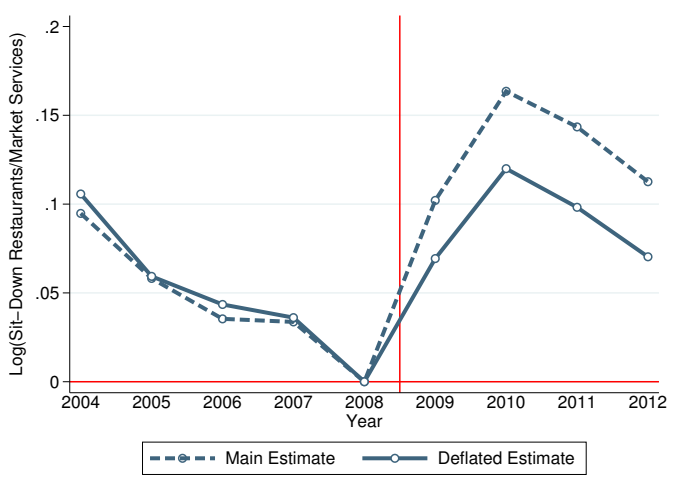

b. Cost per Employee

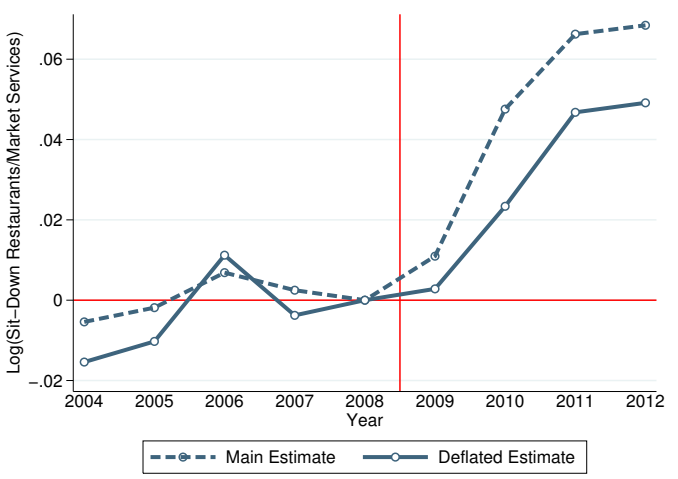

d. Cost of Materials

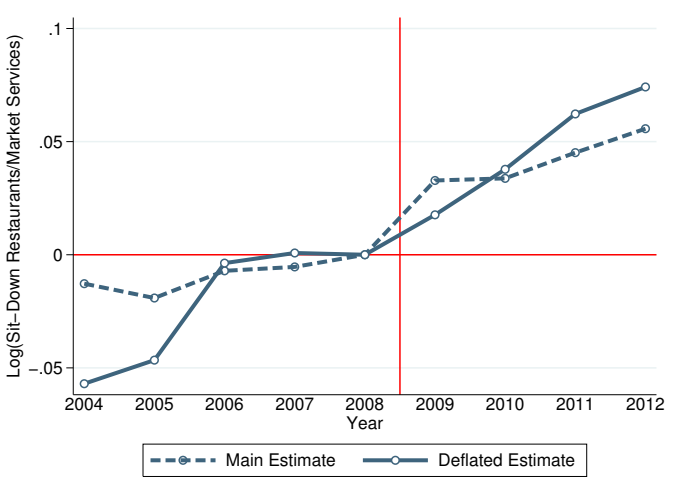

Notes: These Figures are generated by subtracting event-type coefficients computed for hotel sector vs. non-restaurant market services from the event-type coefficients found using equation (1) on sit-down restaurants vs. non-restaurant market services to account for the effect of the removal of the payroll tax subsidy. 
Figure 7: Welfare Effect of VAT Decrease on Consumers if Full Pass-Through

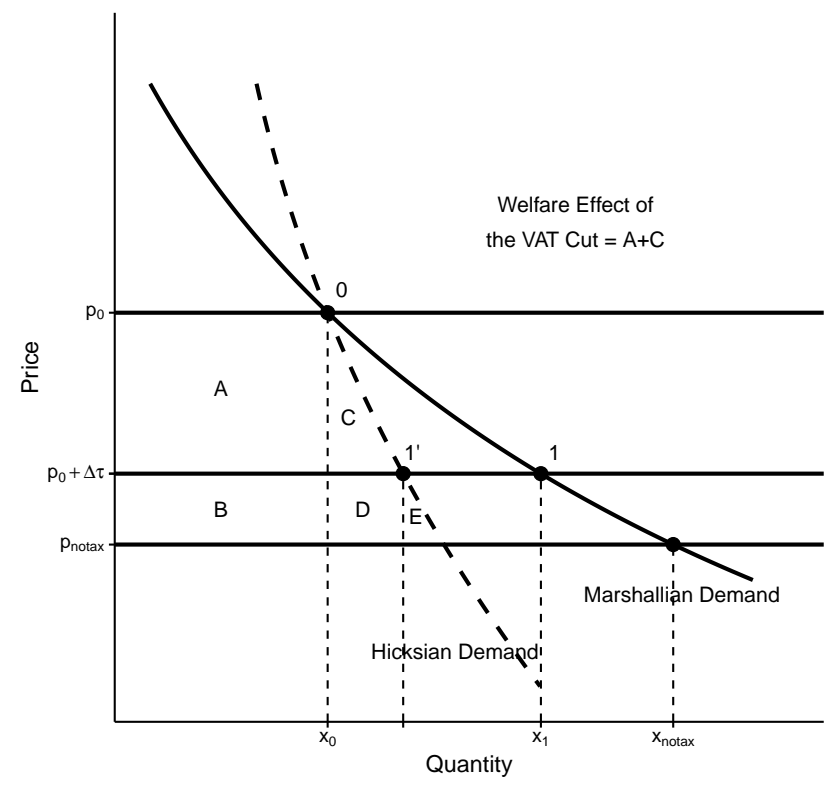

Notes: $p_{0}$ is the pre-reform price of the good, corresponding to a VAT tax rate of 19.6. $p_{0}+\Delta \tau$ is the pre-reform price plus the change in the tax rate. If there is full pass-through to prices, then the welfare effect of the VAT decrease on consumers corresponds to the change in tax revenue (keeping quantities fixed), implying a 100 percent incidence on consumers.

Figure 8: Estimated Incidence of the VAT Reform

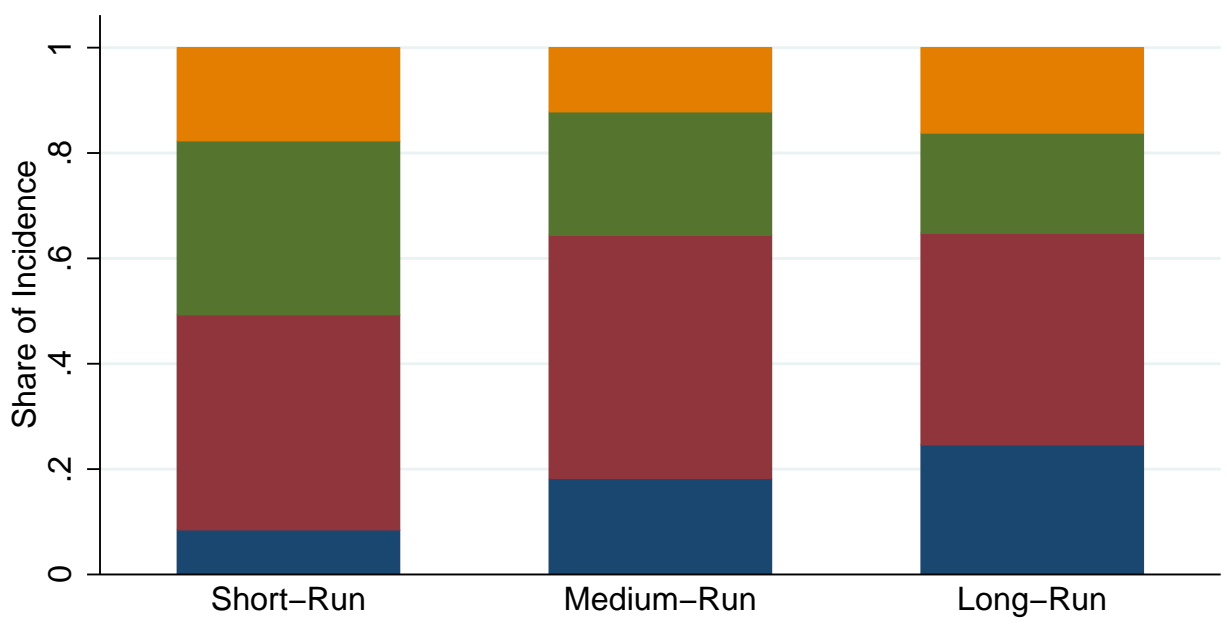

\begin{tabular}{|l|l|}
\hline Employees & Firm Owners \\
\hline Consumers & Sellers of Material Goods \\
\hline
\end{tabular}

Notes: Incidence shares are computed using equation (5). The short-run denotes December 2009, the medium-run December 2010 and the long-run December 2011. 
Figure 9: Dynamic Effects of the VAT Cut: Sit-Down Restaurants vs. Small Firms

a. Number of Employees

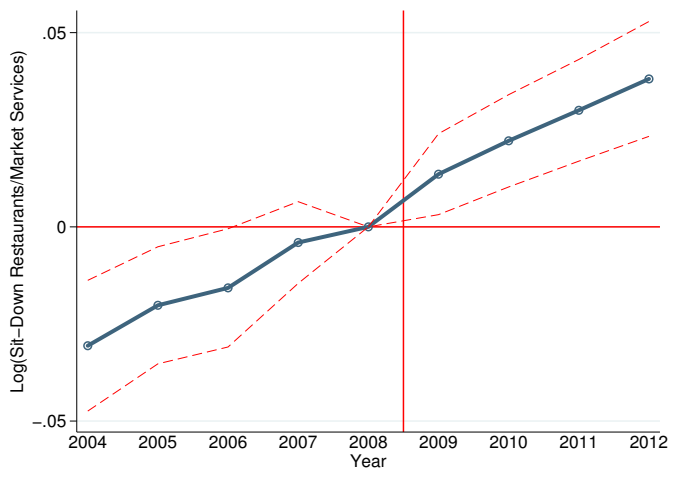

c. Return to Capital

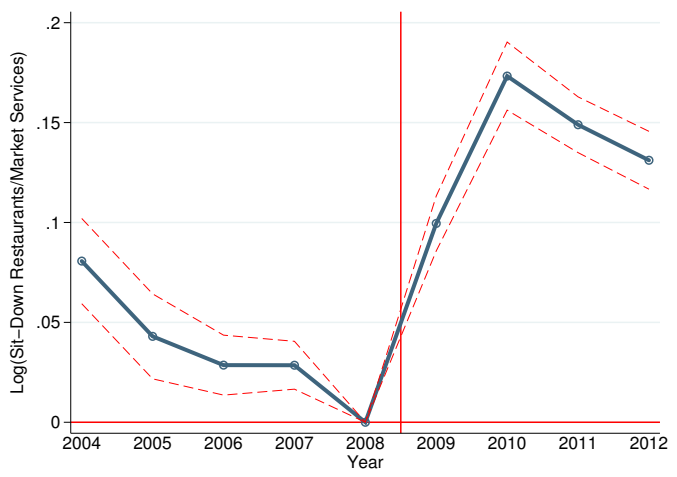

b. Cost per Employee

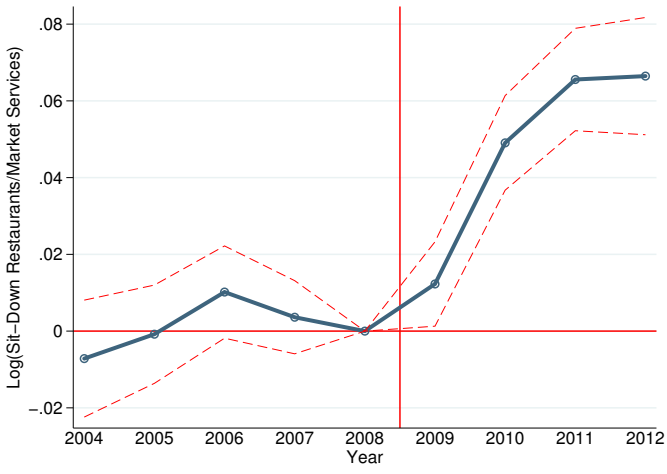

d. Cost of Materials

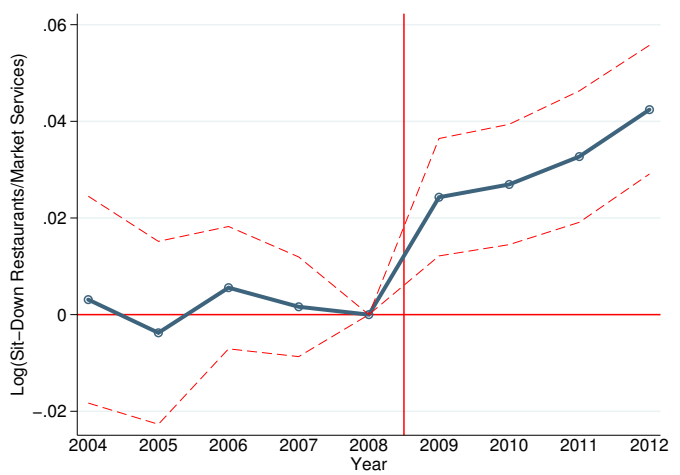

Notes: The Figures show the dynamic effects of the reform estimated using equation (2), which includes year and firm fixed effects. The treatment group includes all sit-down restaurants, while the control group includes all non-restaurant small firms. The dashed lines represent 95 percent confidence intervals. 
Table 1: Outcome Variables: Sit-Down Restaurants vs. Control Groups for 2004-2012

\begin{tabular}{lccc}
\hline \hline & Treatment Group & \multicolumn{2}{c}{ Control Groups } \\
\cline { 3 - 4 } & Sit-Down & Non-Restaurant & Non-Restaurant \\
& Restaurants & Market Services & Small Firms \\
& $(1)$ & $(2)$ & $(3)$ \\
\hline Profit/Loss before tax & 16,165 & 91,489 & 16,314 \\
& $(7,233)$ & $(17,439)$ & $(8,448)$ \\
Operating revenue (Turnover) & 438,169 & $2,871,716$ & 382,476 \\
& $(269,187)$ & $(494,925)$ & $(281,683)$ \\
Sales & 426,683 & $2,798,209$ & 374,341 \\
& $(261,938)$ & $(482,643)$ & $(275,886)$ \\
Number of employees & 5.510 & 11.37 & 3.569 \\
Costs of employees & $(4)$ & $(3)$ & $(2)$ \\
Material costs & 168,813 & 497,571 & 129,637 \\
& $(99,214)$ & $(139,562)$ & $(93,300)$ \\
& 127,173 & $2,208,138$ & 147,482 \\
Observations & $(81,714)$ & $(206,779)$ & $(80,774)$ \\
\hline \hline
\end{tabular}

Notes: All amounts are in real terms (2012 euros). Mean values with median values in parenthesis.

Table 2: Mean Impact Estimates

\begin{tabular}{|c|c|c|c|c|c|}
\hline & $\begin{array}{c}\text { Number of } \\
\text { Employees } \\
(1)\end{array}$ & $\begin{array}{c}\text { Cost per } \\
\text { Employee } \\
(2) \\
\end{array}$ & $\begin{array}{c}\text { Return } \\
\text { to Capital } \\
(3)\end{array}$ & $\begin{array}{c}\text { Profit or } \\
\text { Loss } \\
(4)\end{array}$ & $\begin{array}{c}\text { Cost of } \\
\text { Materials } \\
(5)\end{array}$ \\
\hline After $\times$ Sit-Down Restaurant & $\begin{array}{c}0.0012 \\
(0.0064)\end{array}$ & $\begin{array}{c}0.039^{* * *} \\
(0.0051)\end{array}$ & $\begin{array}{c}0.099^{* * *} \\
(0.0066)\end{array}$ & $\begin{array}{c}0.18^{* * *} \\
(0.013)\end{array}$ & $\begin{array}{c}0.044^{* * *} \\
(0.0053)\end{array}$ \\
\hline $\mathrm{R}^{2}$ & 0.95 & 0.81 & 0.82 & 0.74 & 0.95 \\
\hline Observations & 994,389 & 994,389 & 994,389 & 710,008 & 994,389 \\
\hline Year FE & Yes & Yes & Yes & Yes & Yes \\
\hline Firm FE & Yes & Yes & Yes & Yes & Yes \\
\hline
\end{tabular}

Notes: Coefficients on the interaction variable are average percent changes of the outcome variable estimated using (1) on the period 2004-2011. The control group used is firms operating in non-restaurant market services. Standard errors are clustered by département ${ }^{* * *} \mathrm{p}<0.01$. 
Table 3: Hours Worked: Sit-Down Restaurants vs. Non-Restaurant Market Services

\begin{tabular}{lcccc}
\hline \hline & \multicolumn{5}{c}{ Panel A: Total Hours } \\
\hline After $\times$ Sit-Down Restaurants & -0.017 & -0.014 & -0.016 & 0.0038 \\
& $(0.015)$ & $(0.016)$ & $(0.016)$ & $(0.016)$ \\
After & $0.025^{* * *}$ & $0.048^{* * *}$ & $0.045^{* * *}$ & 0.00087 \\
& $(0.0031)$ & $(0.0055)$ & $(0.0052)$ & $(0.0058)$ \\
& & & \\
Sit-Down Restaurants & $0.034^{* * *}$ & $0.031^{* * *}$ & $0.031^{* * *}$ & $0.051^{* * *}$ \\
& $(0.0092)$ & $(0.0093)$ & $(0.0094)$ & $(0.0087)$ \\
\hline $\mathrm{R}^{2}$ & 0.00057 & 0.0039 & 0.011 & 0.13 \\
Observations & 284,602 & 284,602 & 284,602 & 215,052 \\
\hline \hline & & Panel B: Days Worked & \\
\hline After $\times$ Sit-Down Restaurants & 0.015 & 0.015 & 0.016 & 0.015 \\
& $(0.011)$ & $(0.010)$ & $(0.010)$ & $(0.011)$ \\
After & -0.0037 & -0.0034 & $0.0029^{* * *}$ & $0.0058^{* * *}$ \\
& $(0.0024)$ & $(0.0024)$ & $(0.00037)$ & $(0.00044)$ \\
Sit-Down Restaurants & & & \\
& $0.027^{* *}$ & $0.027^{* *}$ & $0.027^{* *}$ & $0.032^{* * *}$ \\
\hline Observations & $(0.010)$ & $(0.010)$ & $(0.0099)$ & $(0.010)$ \\
\hline \hline Region FE & 93,538 & 93,538 & 93,538 & 79,264 \\
Region $\times$ After & No & Yes & Yes & Yes \\
\hline \hline
\end{tabular}

Notes: Reported coefficients are percent changes in hours worked estimated using year and region fixed effects. Pretreatment period is 2004-2008, while the post-treatment period includes $2009-2012 .{ }^{*} \mathrm{p}<0.10,{ }^{* *} \mathrm{p}<0.05,{ }^{* * *} \mathrm{p}<0.01$

Table 4: Effect of Hiring Subsidy Cut

\begin{tabular}{lccccc}
\hline \hline & $\begin{array}{c}\text { Number of } \\
\text { Employees } \\
(1)\end{array}$ & $\begin{array}{c}\text { Cost per } \\
\text { Employee } \\
(2)\end{array}$ & $\begin{array}{c}\text { Return } \\
\text { to Capital } \\
(3)\end{array}$ & $\begin{array}{c}\text { Profit } \\
\text { or Loss } \\
(4)\end{array}$ & $\begin{array}{c}\text { Cost of } \\
\text { Materials } \\
(5)\end{array}$ \\
\hline After $\times \mathrm{SC}$ & $-0.017^{* * *}$ & 0.010 & $0.058^{* * *}$ & $0.081^{* * *}$ & -0.014 \\
& $(0.0060)$ & $(0.0064)$ & $(0.0069)$ & $(0.021)$ & $(0.016)$ \\
\hline $\mathrm{R}^{2}$ & 0.95 & 0.81 & 0.82 & 0.74 & 0.95 \\
Observations & $1,033,231$ & $1,033,231$ & $1,033,231$ & 734,290 & $1,033,231$ \\
\hline Year FE & Yes & Yes & Yes & Yes & Yes \\
Firm FE & Yes & Yes & Yes & Yes & Yes \\
\hline \hline
\end{tabular}

Notes: Reported coefficients are percent changes in hotels (which are affected by the subsidy cut) relative to firms in non-restaurant market services. The pre-treatment period is 2004-2008, while the posttreatment period includes 2009-2011. ${ }^{*} \mathrm{p}<0.10,{ }^{* *} \mathrm{p}<0.05,{ }^{* * *} \mathrm{p}<0.01$ 
Table 5: Incidence of the VAT Reform

\begin{tabular}{|c|c|c|c|c|}
\hline & \multicolumn{4}{|c|}{ Panel A: Short-Run Incidence } \\
\hline & Estimated & Sales & Weighted & Share of \\
\hline & Percent Change & Share & Percent Change & Incidence \\
\hline Cost of Employees & 0.015 & 39.3 & 0.006 & 8.6 \\
\hline Return to Capital & 0.098 & 29.4 & 0.029 & 41.4 \\
\hline Cost of Materials & 0.038 & 31.3 & 0.012 & 17.1 \\
\hline \multirow[t]{4}{*}{ Prices } & -0.023 & - & -0.023 & 32.9 \\
\hline & \multicolumn{4}{|c|}{ Panel B: Medium-Run Incidence } \\
\hline & Estimated & Sales & Weighted & Share of \\
\hline & Percent Change & Share & Percent Change & Incidence \\
\hline Cost of Employees & 0.047 & 39.3 & 0.018 & 17.7 \\
\hline Return to Capital & 0.162 & 29.4 & 0.048 & 47.0 \\
\hline Cost of Materials & 0.039 & 31.3 & 0.012 & 11.8 \\
\hline \multirow[t]{4}{*}{ Prices } & -0.024 & - & -0.024 & 23.5 \\
\hline & \multicolumn{4}{|c|}{ Panel C: Long-Run Incidence } \\
\hline & Estimated & Sales & Weighted & Share of \\
\hline & Percent Change & Share & Percent Change & Incidence \\
\hline Cost of Employees & 0.064 & 39.3 & 0.025 & 24.5 \\
\hline Return to Capital & 0.142 & 29.4 & 0.042 & 41.2 \\
\hline Cost of Materials & 0.052 & 31.3 & 0.016 & 15.7 \\
\hline Prices & -0.019 & - & -0.019 & 18.6 \\
\hline
\end{tabular}

Notes: Percent changes for the cost per employee, the return to capital and the cost of material goods are estimated using the event-type coefficients computed from equation (2). The change in prices is computed from the log-difference in prices between sit-down restaurants and non-restaurant market services. Sales shares reported in the Table are firm averages in the pre-reform year 2008. Incidence estimates are computed using equation (5).

Table 6: Approximation Error

\begin{tabular}{lccc}
\hline \hline & $\begin{array}{c}\text { Short-Run: } \\
\text { 6 Months } \\
\text { after Reform }\end{array}$ & $\begin{array}{c}\text { Medium-Run: } \\
\text { 18 Months } \\
\text { after Reform }\end{array}$ & $\begin{array}{c}\text { Long-Run: } \\
\text { 30 Months } \\
\text { after Reform }\end{array}$ \\
\hline$d \tau(1-\delta)+\tau\left(d \ln p_{x}-\delta d l n c_{x}\right)$ & 0.091 & 0.090 & 0.091 \\
Sum of Numerators & 0.070 & 0.102 & 0.102 \\
\hline Approximation Error & 0.021 & 0.012 & 0.011 \\
\hline \hline
\end{tabular}

Notes: Table compares sum of numerators in equation (5) to the denominator of the same equation. 
Table 7: Incidence of the VAT Reform using Counterfactual Price and Return to Capital

\begin{tabular}{|c|c|c|c|c|c|c|}
\hline & \multicolumn{6}{|c|}{ Panel A: Short-Run Incidence } \\
\hline & \multicolumn{3}{|c|}{ Counterfactual Price } & \multicolumn{3}{|c|}{ Counterfactual Return to Capital } \\
\hline & $\begin{array}{c}\text { Estimated } \\
\text { Percent Change }\end{array}$ & $\begin{array}{c}\text { Weighted } \\
\text { Percent Change }\end{array}$ & $\begin{array}{c}\text { Share of } \\
\text { Incidence }\end{array}$ & $\begin{array}{c}\text { Estimated } \\
\text { Percent Change }\end{array}$ & $\begin{array}{c}\text { Weighted } \\
\text { Percent Change }\end{array}$ & $\begin{array}{l}\text { Share of } \\
\text { Incidence }\end{array}$ \\
\hline Cost of Employees & 0.015 & 0.006 & 9.7 & 0.015 & 0.006 & 7.9 \\
\hline Return to Capital & 0.098 & 0.029 & 46.9 & 0.119 & 0.035 & 46.1 \\
\hline Cost of Materials & 0.038 & 0.012 & 19.4 & 0.038 & 0.012 & 15.8 \\
\hline \multirow[t]{4}{*}{ Prices } & -0.015 & -0.015 & 24.2 & -0.023 & -0.023 & 30.2 \\
\hline & \multicolumn{6}{|c|}{ Panel B: Medium-Run Incidence } \\
\hline & \multicolumn{3}{|c|}{ Counterfactual Price } & \multicolumn{3}{|c|}{ Counterfactual Return to Capital } \\
\hline & $\begin{array}{c}\text { Estimated } \\
\text { Percent Change }\end{array}$ & $\begin{array}{c}\text { Weighted } \\
\text { Percent Change }\end{array}$ & $\begin{array}{c}\text { Share of } \\
\text { e Incidence }\end{array}$ & $\begin{array}{c}\text { Estimated } \\
\text { Percent Change }\end{array}$ & $\begin{array}{c}\text { Weighted } \\
\text { Percent Change }\end{array}$ & $\begin{array}{l}\text { Share of } \\
\text { e Incidence }\end{array}$ \\
\hline Cost of Employees & 0.047 & 0.018 & 19.1 & 0.047 & 0.018 & 15.8 \\
\hline Return to Capital & 0.162 & 0.048 & 51.1 & 0.204 & 0.060 & 52.6 \\
\hline Cost of Materials & 0.039 & 0.012 & 12.8 & 0.038 & 0.012 & 15.8 \\
\hline \multirow[t]{4}{*}{ Prices } & -0.016 & -0.016 & 17.0 & -0.024 & -0.024 & 21.1 \\
\hline & \multicolumn{6}{|c|}{ Panel C: Long-Run Incidence } \\
\hline & \multicolumn{3}{|c|}{ Counterfactual Price } & \multicolumn{3}{|c|}{ Counterfactual Return to Capital } \\
\hline & $\begin{array}{c}\text { Estimated } \\
\text { Percent Change }\end{array}$ & $\begin{array}{c}\text { Weighted } \\
\text { Percent Change }\end{array}$ & $\begin{array}{c}\text { Share of } \\
\text { Incidence }\end{array}$ & $\begin{array}{c}\text { Estimated } \\
\text { Percent Change }\end{array}$ & $\begin{array}{c}\text { Weighted } \\
\text { Percent Change }\end{array}$ & $\begin{array}{l}\text { Share of } \\
\text { Incidence }\end{array}$ \\
\hline Cost of Employees & 0.064 & 0.025 & 26.6 & 0.064 & 0.025 & 20.8 \\
\hline Return to Capital & 0.142 & 0.042 & 44.7 & 0.205 & 0.060 & 50.0 \\
\hline Cost of Materials & 0.052 & 0.016 & 17.0 & 0.052 & 0.016 & 13.3 \\
\hline Prices & -0.011 & -0.011 & 11.7 & -0.019 & -0.019 & 15.9 \\
\hline
\end{tabular}

Notes: Percent changes for the cost per employee, the return to capital and the cost of material goods are estimated using the event-type coefficients computed from equation (2). The change in prices is computed from the log-difference in prices between sit-down restaurants and non-restaurant market services. Sales shares reported in the Table are firm averages in the pre-reform year 2008. Incidence estimates are computed using equation (5). 
Table 8: Controlling for the Local Unemployment Rate

\begin{tabular}{lccccc}
\hline \hline & $\begin{array}{c}\text { Number of } \\
\text { Employees } \\
\end{array}$ & $\begin{array}{c}\text { Cost per } \\
\text { Employee } \\
(1)\end{array}$ & $\begin{array}{c}\text { Return } \\
\text { to Capital } \\
(2)\end{array}$ & $\begin{array}{c}\text { Profit } \\
\text { or Loss } \\
(3)\end{array}$ & $\begin{array}{c}\text { Cost of } \\
\text { Materials } \\
(5)\end{array}$ \\
\hline After $\times$ Sit-Down Restaurant & 0.00091 & $0.039^{* * *}$ & $0.099^{* * *}$ & $0.18^{* * *}$ & $0.045^{* * *}$ \\
& $(0.0061)$ & $(0.0051)$ & $(0.0067)$ & $(0.013)$ & $(0.0058)$ \\
& & & & & \\
URate $d t$ & $-0.015^{* * *}$ & -0.0038 & 0.00098 & $-0.015^{* *}$ & $0.020^{* *}$ \\
& $(0.0024)$ & $(0.0041)$ & $(0.0051)$ & $(0.0063)$ & $(0.0092)$ \\
\hline $\mathrm{R}^{2}$ & 0.95 & 0.81 & 0.82 & 0.74 & 0.95 \\
Observations $_{\text {Year FE }}$ & 994,389 & 994,389 & 994,389 & 710,008 & 994,389 \\
\hline Firm FE & Yes & Yes & Yes & Yes & Yes \\
\hline \hline
\end{tabular}

Notes: URate $_{d t}$ is departement unemployment rate in year $t$. All specifications include year and firm fixed effects. Standard errors are clustered by département. $* \mathrm{p}<0.10,{ }^{* *} \mathrm{p}<0.05, * * * \mathrm{p}<0.01$

Table 9: Robustness Check: Sit-Down Restaurants vs. Small Firms

\begin{tabular}{lccccc}
\hline \hline & $\begin{array}{c}\text { Number of } \\
\text { Employees } \\
(1)\end{array}$ & $\begin{array}{c}\text { Cost per } \\
\text { Employee } \\
(2)\end{array}$ & $\begin{array}{c}\text { Return } \\
\text { to Capital } \\
(3)\end{array}$ & $\begin{array}{c}\text { Profit } \\
\text { or Loss } \\
(4)\end{array}$ & $\begin{array}{c}\text { Cost of } \\
\text { Materials } \\
(5)\end{array}$ \\
\hline After $\times$ Sit-Down Restaurant & $0.031^{* * *}$ & $0.038^{* * *}$ & $0.11^{* * *}$ & $0.20^{* * *}$ & $0.026^{* * *}$ \\
& $(0.0078)$ & $(0.0047)$ & $(0.0058)$ & $(0.014)$ & $(0.0044)$ \\
\hline $\mathrm{R}^{2}$ & 0.88 & 0.79 & 0.77 & 0.70 & 0.93 \\
Observations & $1,229,883$ & $1,229,883$ & $1,229,883$ & 837,528 & $1,229,883$ \\
\hline Year FE & Yes & Yes & Yes & Yes & Yes \\
Firm FE & Yes & Yes & Yes & Yes & Yes \\
\hline \hline
\end{tabular}

Notes: Coefficients on the interaction variable are average percent changes of the outcome variable estimated using (1) on the period 2004-2011. The control group used is non-restaurant small firms. Standard errors are clustered by département. ${ }^{*} \mathrm{p}<0.10,{ }^{* *} \mathrm{p}<0.05,{ }^{* * *} \mathrm{p}<0.01$ 


\section{APPENDIX FOR ONLINE PUBLICATION}

\section{A Appendix}

\section{A.1 Contrat D'Avenir Details}

The Sarkozy government signed the Contrat D'Avenir in April 2009, at the time of the restaurant VAT reform we are analyzing. The contract was not binding and only involved unionized restaurants, which represent approximately 50 percent of the restaurant industry.

The goal of the contract was to give directives on how to allocate the surplus created by the reduction in the VAT rate. These directives involved four broad categories: employment; prices; investments and modernization of the restaurant sector; and work conditions and social dialogue.

The price directives depended on the type of restaurant:

- Sit-down restaurants were encouraged to reduce prices by $11.8 \%$ for 7 out of the 10 following items: appetizer, entree (meat or fish), daily special, dessert, appetizer-entree menu, entreedessert menu, kid's menu, soda or fruit juice, mineral water, coffee, tea or herbal tea. In case a restaurant did not sell at least seven of these products, it could also reduce prices by $11.8 \%$ for products that represent more than one third of total turnover, excluding alcoholic drinks.

- Although no tax reduction was enacted in take-out restaurants, the government instructed them to reduce price for their reference menus by $5 \%$.

- Cafes and juice bars: a full incidence of the VAT reduction on the price.

The employment directives aimed to create 40,000 jobs over two years in addition to the 15,000 jobs that are created in the restaurant industry every year on average.

The work conditions and social dialogue directives aimed to broadly improve remuneration (for example, faster salary increases over the years), health coverage and training, and to reduce the use of illegal workers.

Finally, the modernization directive aimed at improving employee and customers' safety (including better hygiene), increasing customers' comfort (for example through the purchase of better tables and chairs), the acquisition of environmentally friendly equipment, the renewal of electronic equipment, and increasing the size of the restaurants.

A report by the Ministere de l'Artisanat, du Commerce et du Tourisme ${ }^{43}$ attempts to analyze whether these directives were achieved. A significant issue they struggle with is that no clear measures were established ex-ante. For example, the price drops the directives suggest are not given a time frame making it hard to assess.

It is worth re-emphasizing that these measures were not binding and were not enforced by the government.

\section{A.2 2004-2009 Payroll Tax Reductions}

This government subsidy program, targeting the Hotels Cafés et Réstaurants (HCR) industry, was implemented in 2004 as a temporary measure to help restaurants before the introduction of the VAT cut in 2009. The 2004-804 Law established that firms operating in the HCR sector are eligible for an employment subsidy, initially available for one year and a half. In addition, the 2004-1239 Decree approved on November 22, 2004 defined the criteria for the implementation of the subsidy.

\footnotetext{
${ }^{43}$ Ministry of Craft, Commerce and Tourism.
} 
Table 10: Maximum Monthly Subsidy per Full-Time Employee in 2008

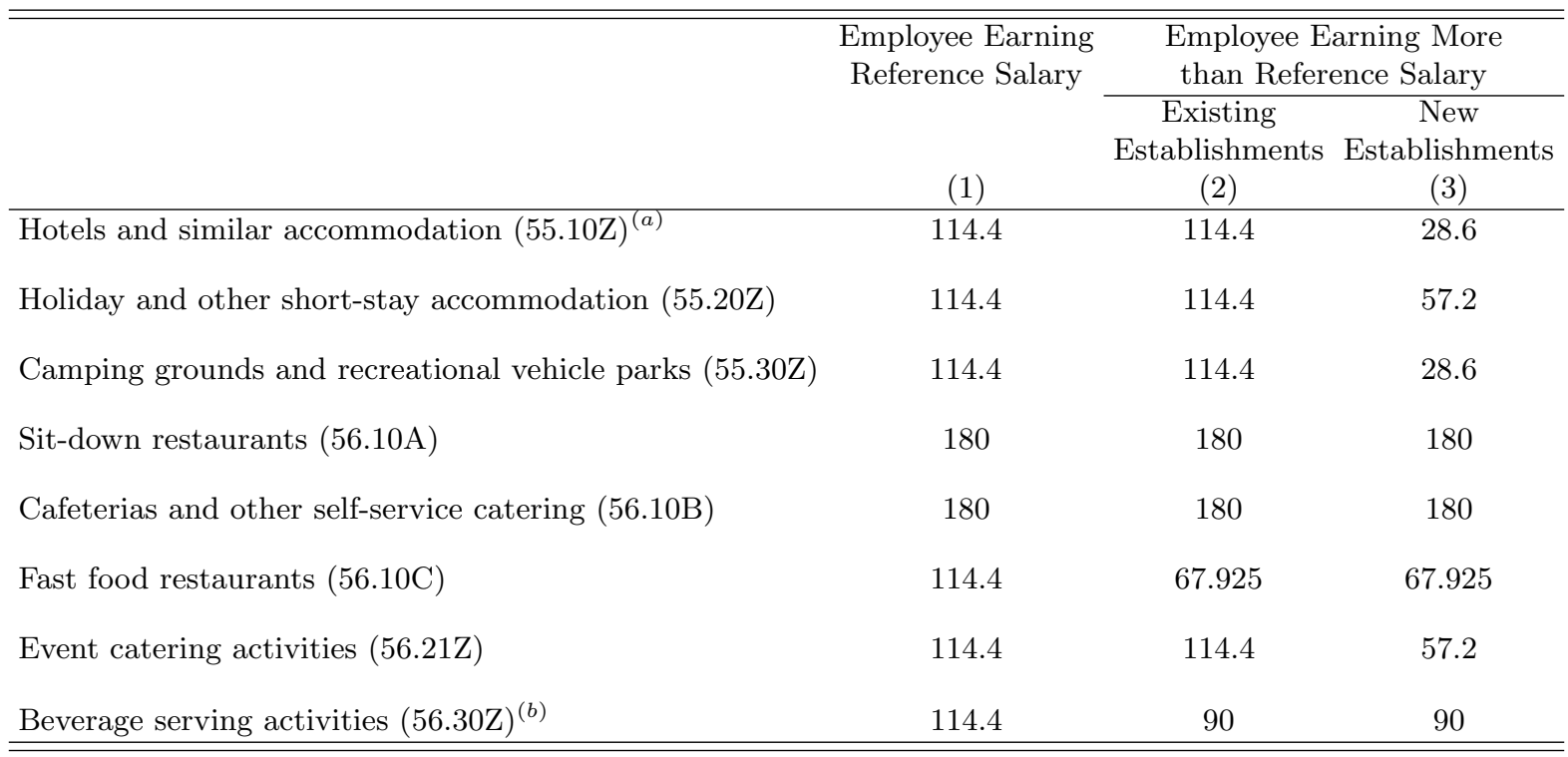

Notes: Reference salary is defined as the minimum wage (SMIC) from 2004 to 2007 and the SMIC plus 3 percent after 2007. Existing establishments have been open for more than a year, while new establishments have operated for a year or less. All amounts are expressed in euros.

(a) Different amounts apply to the sub-category Hôtels touristiques avec restaurant. In this case a new firm hiring an employee earning more than the reference salary gets up to 90 euros.

(b) Both existing and new bowling alleys and casinos receive 28.6 euros for each worker earning more than the reference salary, while both existing and new discos receive 71.5 euros for each worker earning more than the reference salary.

The subsidy was subsequently extended to the period 2006-2008 by the 2005-1719 Law (December 30, 2005), the 2006-1666 Law (December 21, 2006) and the 2007-1822 Law (December 24, 2007), with small changes relative to the original measures. In July 2009, the 2009-888 Law abolished the subsidy, as the VAT cut from 19.6 to 5.5 percent became effective.

Subsidies under this program could not be claimed for the following categories of workers:

- All young workers below 18 years old, who already receive a subsidy of 10-20 percent.

- Employees hired under one of these contracts: (a) contrat jeune en entreprise, (b) contrat initiative emploi, (c) contrat d'apprentissage, (d) contrat d'insertion RMA, (e) contrat de l'aide dégressive a l'employeur (ADE), (f) contrat d'accès a l'emploi dans les DOM.

- Employees for which the employer claims the minimum wage (SMIC) in the hotel industry.

- Employees working in the following sub-industries: hébergements non touristiques (NAF 55.2 F), cantines et restaurants d'entreprise (code NAF 55.5A) and restauration collective sous contrat (NAF 55.5 C)

Notice that though these subsidies were industry-specific, restaurants also received government subsidies that applied to all industries, and that were not abolished in 2009. These included subsidies on contributions paid (allègements de cotisations sociales) established by the January 2003 Fillon law, which could be received on top of the industry specific subsidies, and subsidies for 
firms operating in economically depressed geographic areas, ${ }^{44}$ which a firm could not receive if it claimed the industry specific subsidies. Finally, subsidies received by each firm could not be larger than 200,000 euros over three years, as established by European rules on government subsidies.

\section{A.3 Employment Contract types}

Indeterminate Length Contract Indeterminate Length Contracts (Contrats a Duree Inderterminee) do not have a specific expiry date. Workers are employed for an undetermined length of time. Termination occurs if workers decide to quit, if they are fired or if they retire. If workers are fired, employers are expected to pay them a severance pay. This type of contract usually starts with a 4-month trial period during which the contract can be terminated at no cost.

Determinate Length Contract Determinate Length Contracts (Contrats a Duree Derterminee) have a specific expiry date after which the contract is terminated unless it is renewed for an additional period of time or if the contract is transformed into an Indeterminate Length Contract. It is estimated that there were 2,250,002 such contracts in 2009.

\footnotetext{
${ }^{44}$ These include the Zones Franches Urbaines (ZFU), the Zones de Revitalisation Rurale (ZRR) and the Zones de Redynamisation Urbaine (ZRU)
} 


\section{A.4 Income and Payroll Tax Rates}

Table 11: Marginal Income Tax Rates and Payroll Tax Rates

\begin{tabular}{lll}
\hline \hline Income & $\tau$ & $p$ \\
\hline up to 9,690 euros & $0 \%$ & $50.85 \%$ \\
9,690 to 12,344 euros & $14 \%$ & $41.95 \%$ \\
12,344 to 26,764 euros & $14 \%$ & $21.28 \%$ \\
26,764 to 71,754 euros & $30 \%$ & $21.28 \%$ \\
71,754 to 151,956 euros & $41 \%$ & $21.28 \%$ \\
above 151,956 euros & $45 \%$ & $21.28 \%$ \\
\hline \hline
\end{tabular}

Table 12: Payroll Taxes

\begin{tabular}{|c|c|c|c|c|c|c|}
\hline \multirow[b]{2}{*}{ Monthly Salary } & \multicolumn{6}{|c|}{ Employee Share of Payroll Taxes } \\
\hline & Sickness & Old Age & Family & Unemployment & Retirement & Total \\
\hline 0 to $1.3 \mathrm{~min}$. wage & $0.75 \%$ & $6.75 \%$ & $0 \%$ & $2.40 \%$ & $3.80 \%$ & $13.70 \%$ \\
\hline $1.3 \mathrm{~min}$. wage to 3,086 & $0.75 \%$ & $6.75 \%$ & $0 \%$ & $2.40 \%$ & $3.80 \%$ & $13.70 \%$ \\
\hline 3,086 to 9,258 & $0.75 \%$ & $0.10 \%$ & $0 \%$ & $2.40 \%$ & $8.90 \%$ & $12.15 \%$ \\
\hline 9,259 to 12,344 & $0.75 \%$ & $0.10 \%$ & $0 \%$ & $2.40 \%$ & $0 \%$ & $3.25 \%$ \\
\hline 12,344 to 24,688 & $0.75 \%$ & $0.10 \%$ & $0 \%$ & $0.00 \%$ & $0.33 \%$ & $1.18 \%$ \\
\hline more than 24,988 & $0.75 \%$ & $0.10 \%$ & $0 \%$ & $0.00 \%$ & $0.33 \%$ & $1.18 \%$ \\
\hline & \multicolumn{6}{|c|}{ Employer Share of Payroll Taxes } \\
\hline Monthly Salary & Sickness & Old Age & Family & Unemployment & Retirement & Total \\
\hline 0 to $\min$. wage & $13.10 \%$ & $8.40 \%$ & $5.40 \%$ & $4.30 \%$ & $6.22 \%$ & $37.42 \%$ \\
\hline min. wage to $1.3 \mathrm{~min}$. wage & $13.10 \%$ & $8.40 \%$ & $5.40 \%$ & $4.30 \%$ & $6.22 \%$ & $37.42 \%$ \\
\hline 1.3 to $1.6 \mathrm{~min}$. wage & $13.10 \%$ & $8.40 \%$ & $5.40 \%$ & $4.30 \%$ & $6.22 \%$ & $37.42 \%$ \\
\hline $1.6 \mathrm{~min}$. wage to 3,086 & $13.10 \%$ & $8.40 \%$ & $5.40 \%$ & $4.30 \%$ & $6.22 \%$ & $37.42 \%$ \\
\hline 3,086 to 9,258 & $13.10 \%$ & $1.60 \%$ & $5.40 \%$ & $4.30 \%$ & $14.30 \%$ & $38.70 \%$ \\
\hline 9,259 to 12344 & $13.10 \%$ & $1.60 \%$ & $5.40 \%$ & $4.30 \%$ & $14.30 \%$ & $38.70 \%$ \\
\hline 12,344 to 24,688 & $13.10 \%$ & $1.60 \%$ & $5.40 \%$ & $0 \%$ & $0 \%$ & $20.10 \%$ \\
\hline more than 24,988 & $13.10 \%$ & $1.60 \%$ & $5.40 \%$ & $0 \%$ & $0 \%$ & $20.10 \%$ \\
\hline
\end{tabular}

Notes: This Table reports the share of payroll taxes paid by employers and employees as well as the total payroll taxes paid. 


\section{B Data Appendix}

\section{B.1 Definition of Market Services}

Following level 1 of the French NAF Rev.2 industry classification and the official definition from the French National Institute of Statistics and Economic Studies (INSEE), this group includes: wholesale and retail trade, repair of motor vehicles and motorcycles (section G), accommodation service activities (division 55 in section I), information and communication (section $\mathrm{J}$ ), financial and insurance activities (section K), real estate activities (section L), professional, scientific and technical activities (section M) and administrative and support service activities (section N).

Market services does not include services that are either non-marketable or subsidized by the government such as transportation and storage (section $\mathrm{H}$ ), public administration and defense, compulsory social security (section $\mathrm{O}$ ), education (section $\mathrm{P}$ ), human health and social work activities (section Q), arts, entertainment and recreation (section $\mathrm{R}$ ), and other services (section $\mathrm{S}$ ).

\section{B.2 Goods Produced in Market Services}

\section{Table 13: Services Included in Price Index for Market Services}

\begin{tabular}{cl}
\hline \hline COICOP Code & Description \\
\hline 03.1 .4 & Cleaning, repair and hire of clothing \\
$04.1 .1 / 2$ & Actual rentals paid by tenants including other actual rentals \\
04.3 .2 & Services for the maintenance and repair of the dwelling \\
04.4 .2 & Refuse collection \\
04.4 .3 & Sewage collection \\
04.4 .4 & Other services relating to the dwelling n.e.c. \\
05.1 .3 & Repair of furniture, furnishings and floor coverings \\
05.3 .3 & Repair of household appliances \\
05.6 .2 & Domestic services and household services \\
08.1 .0 & Postal services \\
$08.2 / 3.0$ & Telephone and telefax equipment and telephone and telefax services \\
09.1 .5 & Repair of audio-visual, photographic and information processing equipment \\
11.2 .0 & Accommodation services \\
12.5 .2 & Insurance connected with the dwelling \\
12.5 .3 & Insurance connected with health \\
12.5 .4 & Insurance connected with transport \\
12.5 .5 & Other insurance \\
12.6 .2 & Other financial services n.e.c. \\
12.7 .0 & Other services n.e.c. \\
\hline \hline
\end{tabular}

Notes: This Table reports COICOP codes used by Eurostat to describe price categories included in the service sector and categorized as market services by the INSEE. 


\section{Table 14: Services Excluded from Price Index for Market Services}

\begin{tabular}{cl}
\hline \hline COICOP Code & Description \\
\hline $06.2 .1 / 3$ & Medical and paramedical services \\
06.2 .2 & Dental services \\
06.3 .0 & Hospital services \\
07.2 .3 & Maintenance and repair of personal transport equipment \\
07.2 .4 & Other services in respect of personal transport equipment \\
07.3 .1 & Passenger transport by railway \\
07.3 .2 & Passenger transport by road \\
07.3 .3 & Passenger transport by air \\
07.3 .4 & Passenger transport by sea and inland waterway \\
07.3 .5 & Combined passenger transport \\
07.3 .6 & Other purchased transport services \\
09.2 .3 & Maintenance and repair of other major durables for recreation and culture \\
09.4 .1 & Recreational and sporting services \\
09.4 .2 & Cultural services \\
09.6 .0 & Package holidays \\
$10 . X .0$ & Pre-primary and primary, secondary, post-secondary non-tertiary, \\
& tertiary education, and education not definable by level \\
11.1 .1 & Restaurants, cafes and the like \\
11.1 .2 & Canteens \\
12.1 .1 & Hairdressing salons and personal grooming establishments \\
12.4 .0 & Social protection \\
\hline \hline
\end{tabular}

Notes: This Table reports COICOP codes used by Eurostat to describe price categories included in the service sector but excluded from the market services definition used by INSEE.

\section{Technical Appendix}

In equilibrium, total after-tax firm revenue equals total income, that is:

$$
(1-\tau)\left(p_{x} X-c_{x} M_{x}\right)=w_{x} L_{x}+r_{x} K_{x}
$$

By the envelope theorem, we have:

$$
(1-\tau) p_{x} d X=w_{x} d L_{x}+(1-\tau) c_{x} d M_{x}+r_{x} d K_{x}
$$

In this case the first order effect of the tax is given by:

$$
X d\left(\tau p_{x}\right)-c_{x} M_{x} d \tau-\tau M_{x} d c_{x}=X d p_{x}+L_{x}\left(-d w_{x}\right)+K_{x}\left(-d r_{x}\right)+M_{x}\left(-d c_{x}\right)
$$

from which:

$$
\begin{aligned}
& \frac{X d p_{x}}{X d\left(\tau p_{x}\right)-c_{x} M_{x} d \tau-\tau M_{x} d c_{x}}-\frac{L_{x} d w_{x}}{X d\left(\tau p_{x}\right)-c_{x} M_{x} d \tau-\tau M_{x} d c_{x}}- \\
& -\frac{K_{x} d r_{x}}{X d\left(\tau p_{x}\right)-c_{x} M_{x} d \tau-\tau M_{x} d c_{x}}-\frac{M_{x} d c_{x}}{X d\left(\tau p_{x}\right)-c_{x} M_{x} d \tau-\tau M_{x} d c_{x}}=1
\end{aligned}
$$


Given the Cobb-Douglas production function, we have $\gamma=\frac{w_{x} L_{x}}{p_{x} X}, \delta=\frac{c_{x} M_{x}}{p_{x} X}$ and $(1-\gamma-\delta)=\frac{r_{x} K_{x}}{p_{x} X}$. It follows that:

$$
\begin{aligned}
& \underbrace{\frac{d \ln p_{x}}{d \tau(1-\delta)+\tau\left(d \ln p_{x}-\delta d \ln c_{x}\right)}}_{\text {Share on Consumers }}-\underbrace{\frac{d \ln w_{x}}{d \tau(1-\delta)+\tau\left(d \ln p_{x}-\delta d \ln c_{x}\right)}}_{\text {Share on Employees }} \\
& -\underbrace{(1-\gamma-\delta) \frac{d \ln r_{x}}{d \tau(1-\delta)+\tau\left(d \ln p_{x}-\delta d \ln c_{x}\right)}}_{\text {Share on Capital Owners }}-\underbrace{\delta \frac{d(1-\delta)+\tau\left(d \ln p_{x}-\delta d \ln c_{x}\right)}{d \tau(1-\delta)}}_{\text {Share on Sellers of Material Goods }}=1
\end{aligned}
$$




\section{Appendix Figures}

Figure A.1: Unconditional Means: Sit-Down Restaurants vs. Market Services

a. Number of Employees

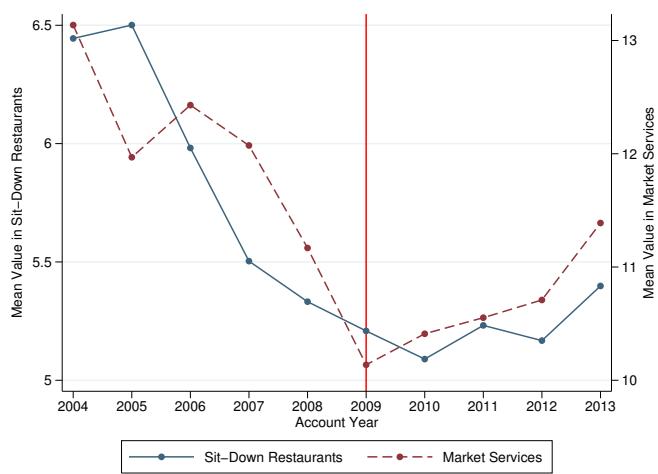

c. Profit or Loss

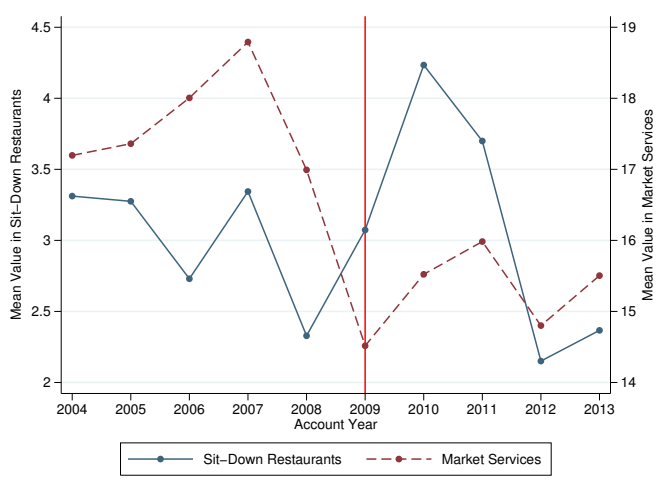

b. Cost per Employee

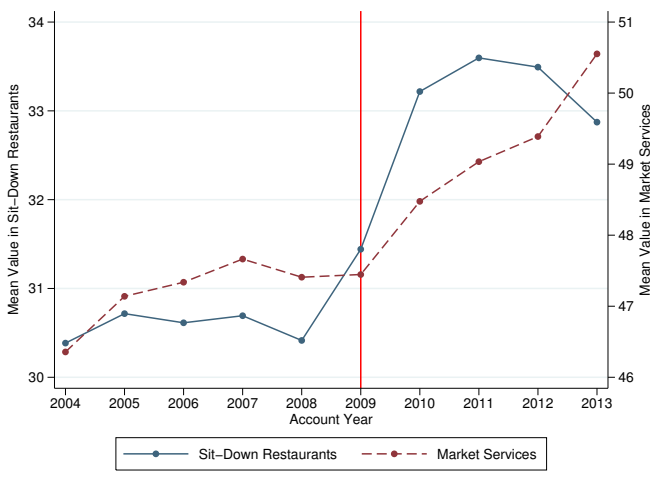

d. Cost of Materials

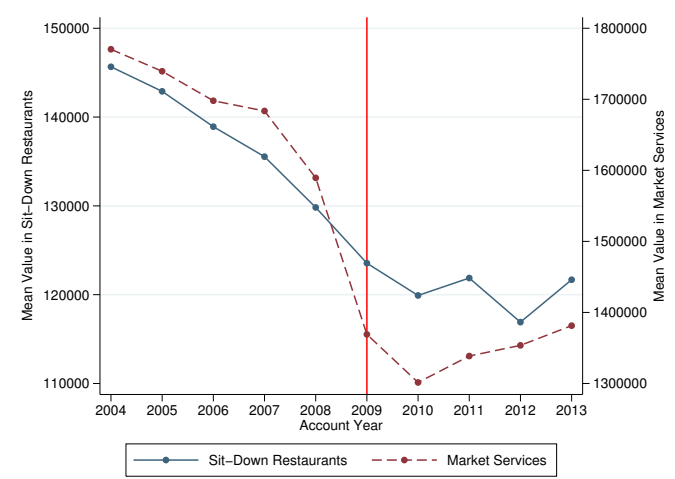

Notes: Computed using data on French sit-down restaurants from AMADEUS. All amounts are expressed in 2012 euros. The treatment group includes French sit-down restaurants, while the control group includes all firms in non-restaurant market service sectors (see the data appendix for details). Information is taken from restaurants' unconsolidated balance sheets. The top 1 percent and the bottom 1 percent of the profit-loss distribution are excluded from both the treatment and the control group. 
Figure A.2: Firm Entry and Exit

a. Number of Employees

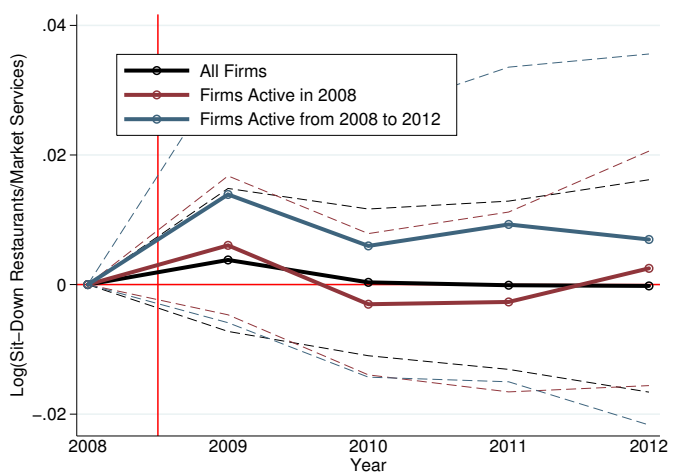

c. Return to Capital

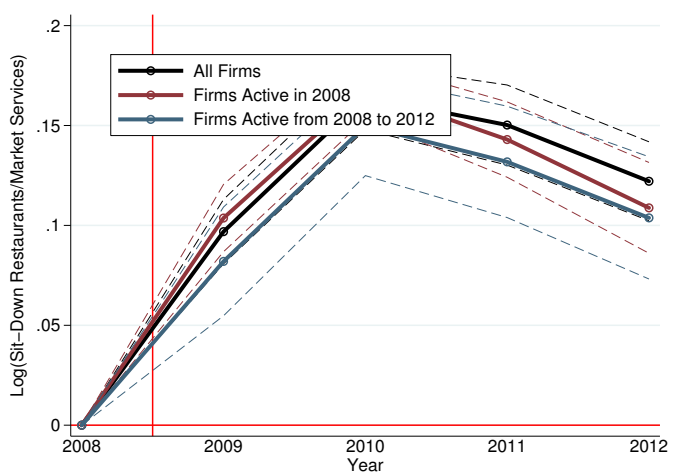

b. Cost of Employees

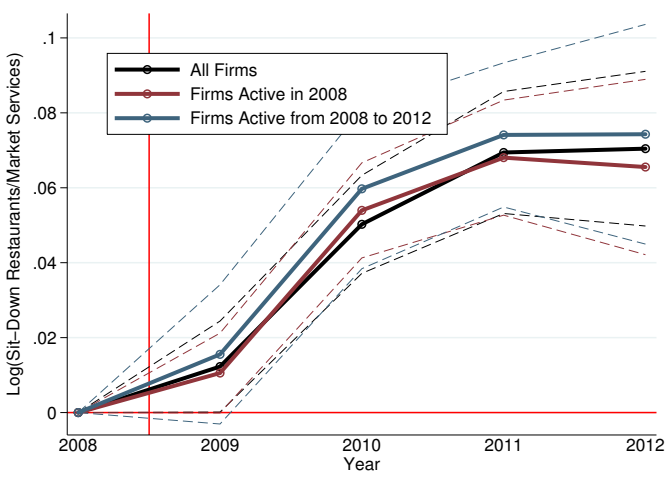

d. Cost of Materials

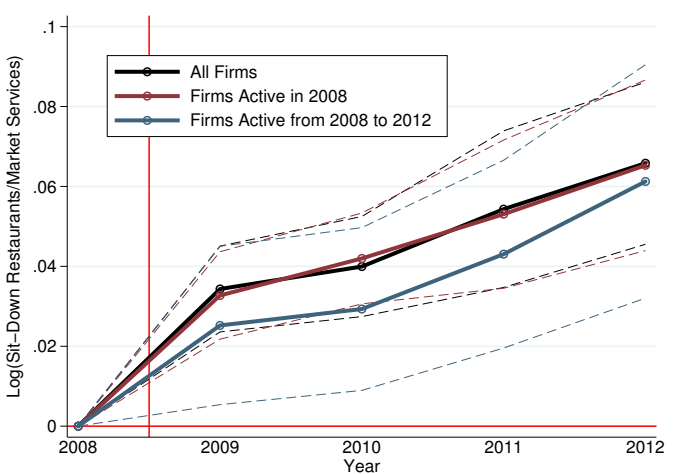

Notes: Figure shows coefficients estimated using equation (2) on the period 2008-2012. The treatment group includes sit-down restaurants, while the control group includes all firms in non-restaurant market services. The dashed lines represent 95 percent confidence intervals. All firms includes both firms which were active in 2008, and firms that entered the sample later on. Firms active in 2008 only includes firms which were active in 2008 but not necessarily active in 2009-2012. Finally, Firms active from 2008 to 2012 includes firms which were active in 2008 and did not exit the sample in period 2009-2012. 
Figure A.3: Prices Event-Time Estimates: Sit-Down Restaurants vs. Non-Restaurant Firms

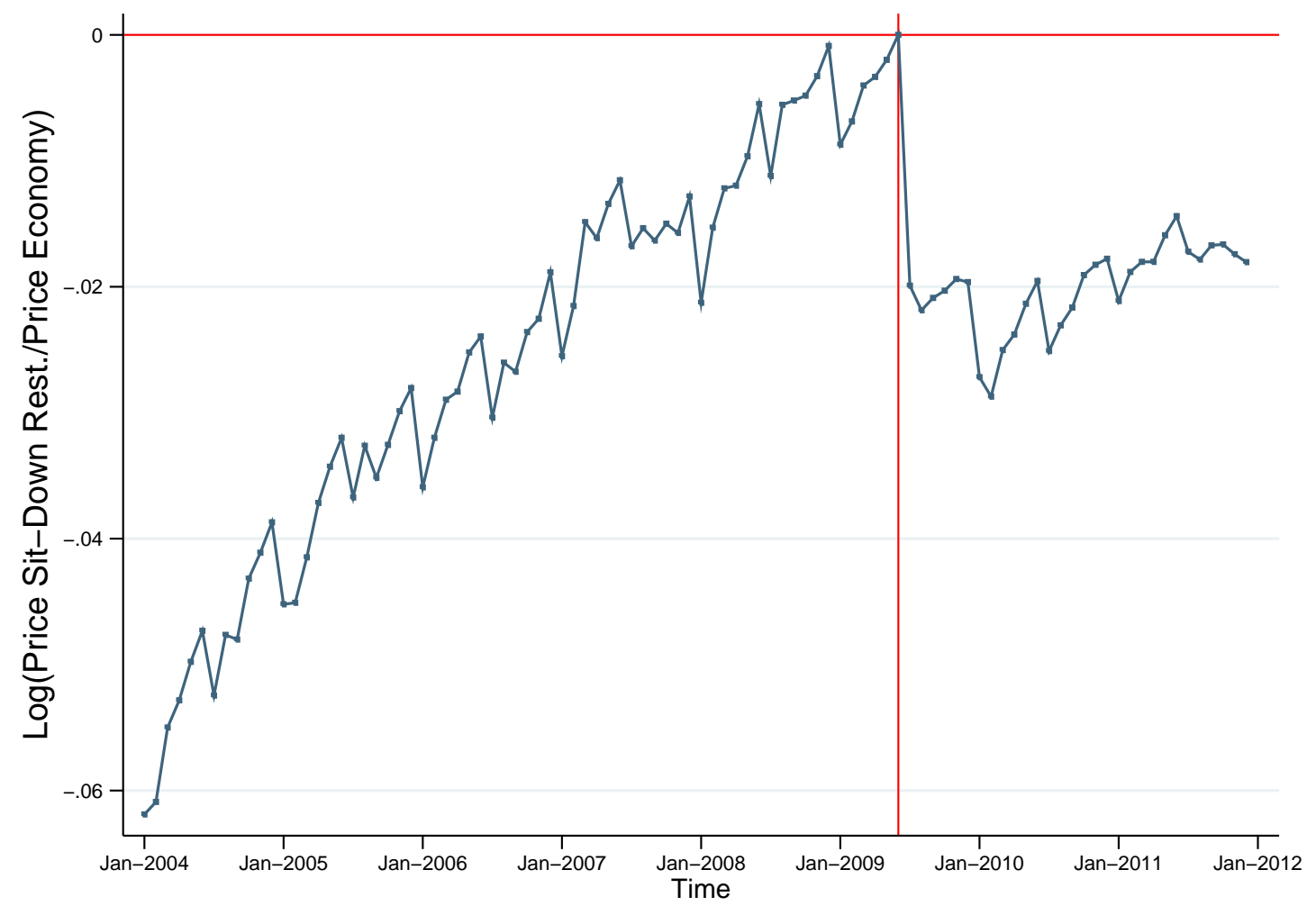

Source: INSEE and authors' computations on Eurostat data. 
Figure A.4: Dynamic effects on Full-Sample: Sit-Down Restaurants vs. Market Services

a. Cost of Employees

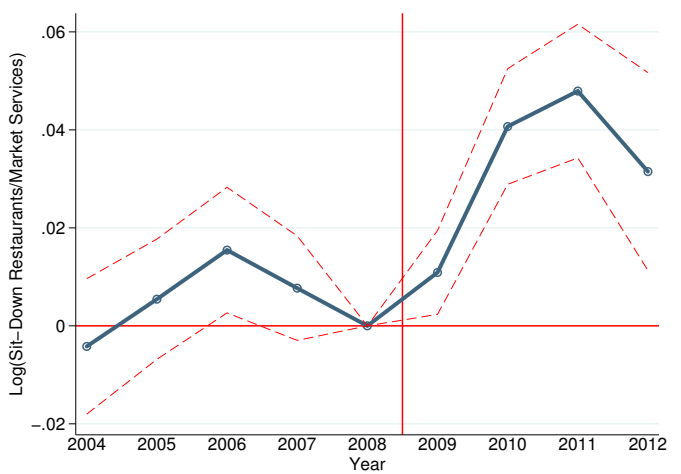

c. Profit or Loss

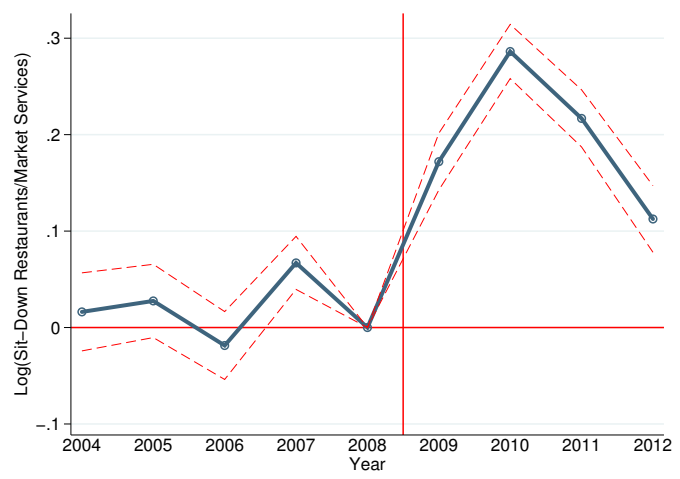

b. Return to Capital

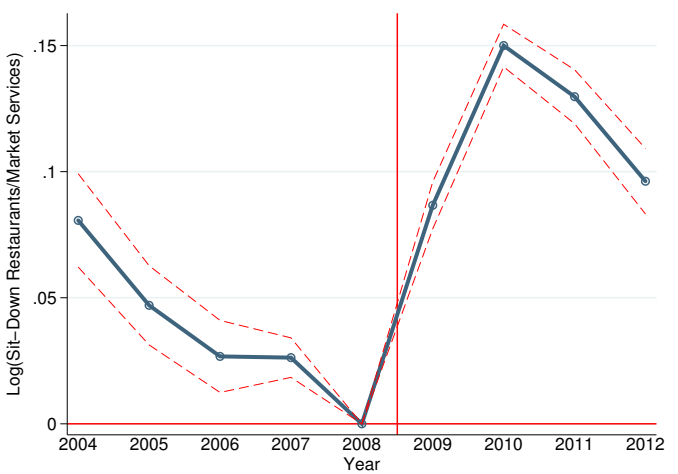

d. Cost of Materials

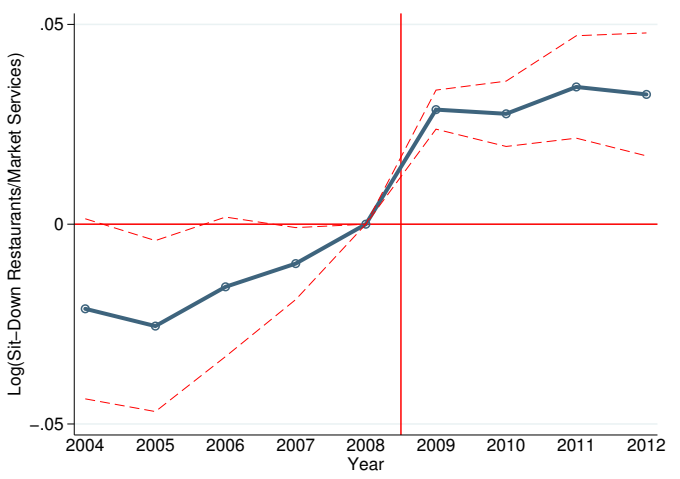

Notes: The Figures show the dynamic effects of the reform estimated using equation (2), which includes year and firm fixed effects. The treatment group includes all sit-down restaurants, while the control group includes firms in non-restaurant market service sectors. The Figures consider the full sample of firms with unconsolidated balance sheets. The dashed lines represent 95 percent confidence intervals. 